\title{
Como conduzir um exercício de cobertura: Uma ferramenta para a avaliação rápida de programas e serviços
}

\author{
Carey Meyers \\ Population Council \\ Solene Lardoux
}

Follow this and additional works at: https://knowledgecommons.popcouncil.org/departments_sbsr-pgy

Part of the Demography, Population, and Ecology Commons, Family, Life Course, and Society Commons, International Public Health Commons, and the Quantitative, Qualitative, Comparative, and Historical Methodologies Commons How does access to this work benefit you? Let us know!

\section{Recommended Citation}

Meyers, Carey and Solene Lardoux. 2006. "Como conduzir um exercício de cobertura: Uma ferramenta para a avaliação rápida de programas e serviços." New York: Population Council. 


\section{Como Conduzir Um Exercício de Cobertura: Uma ferramenta para a Avaliação Rápida de Programas e Serviços}

* Como Conduzir Um Exercício de Cobertura está disponível também em inglês, francês e espanhol.

\section{(1) Population Council}

Juillet 2006

Copyright @ 2006 The Population Council, Inc. 


\section{(2) Population Council}

\section{AGRADECIMENTOS}

O conceito original de um exercício de cobertura (EC) foi apresentado numa reunião do Population Council/Fundo das Nações Unidas para Atividades da População (UNFPA) nos dias 1 a 3 de maio de 2002 em Nova York. Um documento com os resultados da discussão foi publicado com o título de "“Transitions to Adulthood: Adolescent and Youth Sexual and Reproductive Health: Charting directions for a second generation of programming" (transições para a vida adulta: saúde sexual e reprodutiva de adolescentes e jovens: Instruções norteadoras para uma segunda geração de programas de ação" (2003). A idéia de um exercício de cobertura foi lançada por Judith Bruce no $2^{\circ}$ capítulo do documento, "Etapas na Construção de Programas Baseados em Evidências para Adolescentes" (disponível on-line em http://www.popcouncil.org/pdfs/AYSRH/2jb1.pdf).

O primeiro exercício de cobertura foi conduzido na Etiópia em 2003 pelo Population Council (Annabel Erulkar e Tekle-Ab Mekbib) em colaboração com a entidade Private Associations Cooperating Together (PACT, financiada pela USAID) e 13 organizações de atendimento à juventude. Os dados foram primeiramente apresentados em seminários com entidades parceiras em 2004, e publicados em 2005 (Mekbib, Erulkar e Belete, 2005).

Foi realizado um exercício de cobertura em Burkina Faso no contexto de uma parceria entre o UNFPA, o Population Council e 20 entidades de atendimento à juventude. Entre os participantes do processo estavam Geneviève Ah Sue e Siaka Traoré do UNFPA e Zio Simplice Batebié como consultor.

Também foram realizados exercícios de cobertura na Mauritânia e na Guiné Bissau através de uma cooperação entre o Population Council, o UNFPA e organizações locais. Entre os participantes do exercício na Mauritânia estão Mohamed Baraket, Seynath Aidara, Elhacen Mohamed Abdellahi, Delphine Vazeilles, Yao Gaspard Bossou do UNFPA, Bih Abdel Kader, Moctar Ould Ndiack da Direção de Juventude e Mohamed Aly Ould Ekeibed como consultor. Entre os participantes do exercício na Guiné Bissau estão Guy de Araujo, Joaquim Gomes, Cândida Lopes da UNFPA, N'kitcha No Obna e Mauricio Sanca do Instituto da Juventude e Plácido Cardoso como consultor.

A elaboração do presente guia pelo Population Council tem o apoio resultante da cooperação com o Futures Group, sob o contrato com a USAID de número HRN-C-00-0000006-00, com apoio adicional por parte do Departamento de Desenvolvimento Internacional (DfID) (através do programa de garotas adolescentes do Population Council) e do UNFPA. Este guia foi elaborado por Carey Meyers e Solène Lardoux, os quais agradecem as contribuições concretas e editoriais de Annabel Erulkar, Heidi Jones, Amy Joyce, Judith Bruce, Saumya RamaRao e colaboradores do Futures Group.

Judith Bruce

Population Council

One Dag Hammarskjold Plaza

New York, NY 10017

212-339-0500 (phone)

jbruce@popcouncil.org

http://www.popcouncil.org 


\section{(1) Population Council}

\section{Índice}

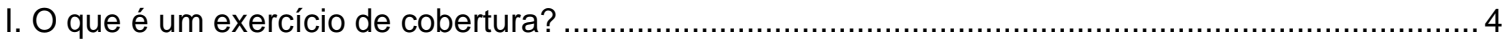

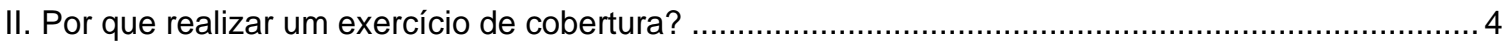

III. Quem pode beneficiar-se de um exercício de cobertura? ...........................................................

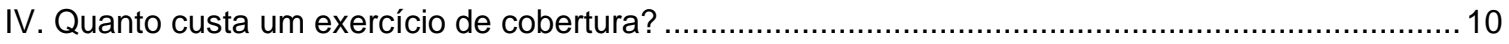

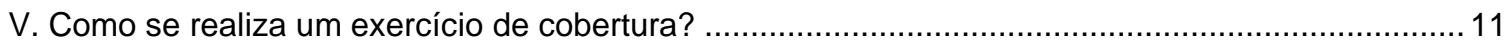

Fase 1. Seleção de parceiros e definição de um formato e quadro de referências comum .................11

Fase 2. Sensibilização da equipe e planejamento geral ............................................................ 13

Finalização da ferramenta de coleta de dados (o registro de atividades)................................... 16

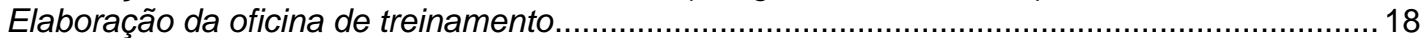

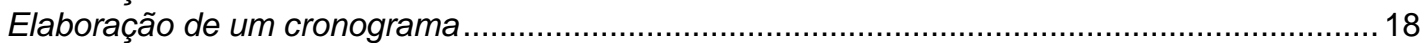

Fase 3. Realização do treinamento e início da coleta de dados.....................................................19

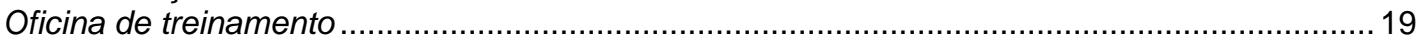

De que maneira os assistentes do projeto podem prestar suporte aos educadores de pares ou

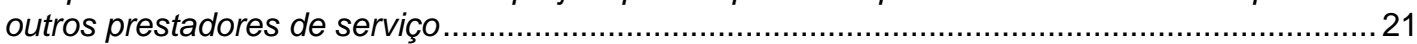

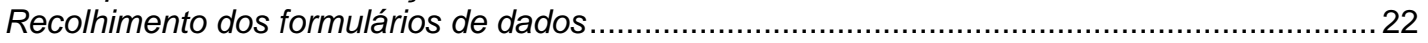

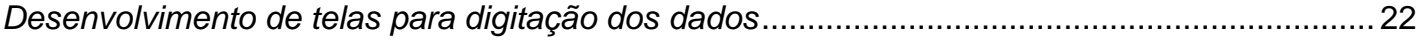

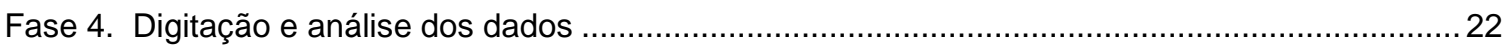

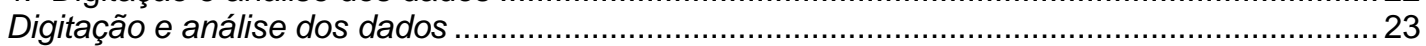

Elaboração de pacotes com resultados preliminares para divulgação ....................................... 25

Fase 5. Divulgação dos dados e reavaliação de programas e políticas em torno da educação de

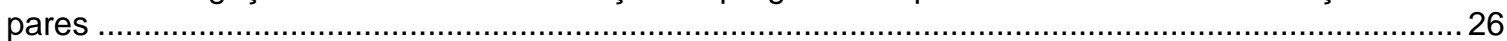

Oficina de divulgação junto a educadores de pares, prestadores de serviço e gestores de

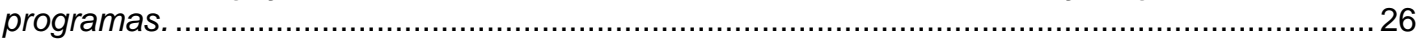

Oficina de divulgação com doadores e patrocinadores, agências governamentais, gestores de

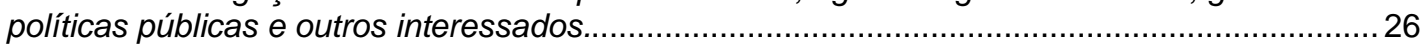

Reestruturação dos programas para melhorar a captação dos que são sub-atendidos pelos

modelos existentes - ou definição de outros métodos para atingir os que atualmente não estão

participando dos programas de multiplicação (educação de pares) ..............................................2

Anexo A.1: Formulário de Coleta de Dados Desenvolvido para Tabulação Manual ............................28

Anexo A.2 Planilha: Mapeamento do Conteúdo de Programas de Adolescentes ..............................29

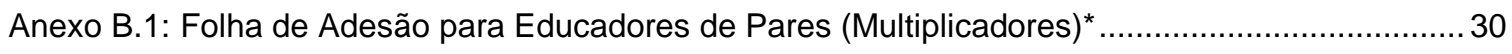

Anexo B.2: Formulário de Coleta de Dados para as Organizações.................................................. 31

Annex B.3: Registro de Atividades Individuais para Educador de Pares ou Prestador de

Serviço.

Anexo B.4: Folha de Adesão para Atividades Grupais de Educadores de Pares* ..............................33

Anexo B.5 Registro de Atividades para um Centro de Juventude .................................................. 34

Anexo C: Programação utilizada no treinamento ocorrido em Burkina Faso..................................... 35

Anexo D: Amostras de resultados do exercício de cobertura na Mauritânia .....................................36 


\section{Population Council}

\section{O que é um exercício de cobertura?}

Um exercício de cobertura (EC) é uma ferramenta de avaliação rápida, simples e de baixo custo que pode ser utilizado para se obter o perfil das pessoas atingidas por um determinado serviço ou grupo de prestadores de serviços ${ }^{1}$ ou organizações com uma clientela comum atuando numa área geográfica definida. Esta ferramenta foi desenvolvida com o intuito de auxiliar programas de atendimento à juventude, mas a mesma também pode ser utilizada com outros beneficiários. Pode ser empregada para um gama de serviços, tanto os realizados numa clínica ou ambulatório bem como na comunidade. Um EC coleta dados sobre uma variedade de características, entre as quais: gênero, escolaridade, nível social, condições de moradia, trabalho, status e estado civil das pessoas que são atendidas por um programa ou serviço. Ela também permite que os funcionários e gestores de programas adquiram uma visão sistemática dos serviços que estão de fato sendo prestados, onde exatamente os mesmos estão sendo prestados e se os beneficiários dos programas, os usuários, retornam ou não. A finalidade última da ferramenta é determinar: 1. se os serviços oferecidos estão atingindo os beneficiários pretendidos e 2. se os serviços são adequados para as pessoas que os recebem.

Um EC fornece a organizações comunitárias, religiosas e não governamentais, programas municipais e agências de cooperação da USAID uma ferramenta básica de monitoramento e avaliação $(\mathrm{M}+\mathrm{A})$ que é simples de utilizar e de baixo custo. Saber se os programas estão ou não atingindo os beneficiários pretendidos ajuda aos executores e aos patrocinadores a concentrar suas atividades e financiamentos de modo a alcançar os que mais os necessitam.

\section{Por que realizar um exercício de cobertura?}

Os pesquisadores do Population Council desenvolveram o EC visando oferecer, a entidades de atendimento à juventude, uma ferramenta sustentável de monitoramento e avaliação que reconheça a diversidade das vidas e populações adolescentes. Reconhecer que adolescentes dotados de diferentes características tais como idade, gênero e estado civil, apresentam também distintas necessidades é um aspecto às vezes desconsiderado, mas essencial para a compreensão das vulnerabilidades de adolescentes (ver quadro abaixo

\footnotetext{
${ }^{1}$ O termo "prestadores de serviço" refere-se a qualquer pessoa que forneça "serviços" tais como intercâmbio de informações em programas onde atuam educadores de pares (multiplicadores) ou agentes que trabalhem em centros de juventude. Não se refere apenas a profissionais da área de saúde.
} 
para maiores detalhes). Uma garota de 12 anos de idade, não casada, fora da escola, que vive afastada de seu lar rural de origem, com "primos" distantes numa região urbana que desconhece, trabalhando como empregada doméstica tem, marcadamente, necessidades diversas de uma garota noiva de 19 anos, já formada no Ensino Médio, que mora com seus pais - e ambas têm necessidades que não são as mesmas de um rapaz de 16 anos numa região semi-rural que é órfão por causa da AIDS e tenta freqüentar a escola ao mesmo tempo em que sustenta e cuida de seus irmãos menores. Os dados nacionais, tais como os coletados nas Pesquisas Demográficas e de Saúde (DHS), podem ajudar a descrever as proporções de adolescentes de um país que se encaixam nestes diferentes tipos de categorias. O quadro abaixo fornece uma descrição detalhada, baseada em dados de DHS, das características que separam os adolescentes uns dos outros. Um EC traz à luz quais adolescentes (ou outras populações que estejam sendo estudadas), de cada um destes tipos de categorias, estão sendo atingidos por programas direcionados a eles, bem como os que não estão sendo atingidos. 
Diversidade de Adolescentes: tabulações do Population Council de dados DHS sobre adolescentes

As tabelas sobre adolescentes do Population Council, "Fatos Relativos a Adolescentes

Provenientes de Pesquisas Demográficas e de Saúde" apresentam informações sobre jovens entre 10 e 24 anos de idade nas seguintes áreas:

- $\quad$ Situação de residência (urbana/rural)

- Distribuição da população

- $\quad$ Condições de moradia

- Situação de sobrevivência dos pais e residência no lar

- Características do/a chefe da casa

- Matrícula e resultados educacionais (urbana/rural)

- Estado civil

- Estado civil atual

- Casados por idades de 15, 18, 20 anos

- Escolaridade de adolescentes e situação de trabalho, por estado civil e criação de filhos

- $\quad$ Atividade sexual e criação de filhos

- Conhecimentos, comportamento e riscos especiais relativos a saúde reprodutiva

- $\quad$ Nível de consciência sobre e utilização de métodos anticoncepcionais

- $\quad$ Nível de consciência sobre HIV/AIDS

- Experiência com doenças sexualmente transmissíveis

- $\quad$ Circuncisão genital feminina (só coletada em alguns países)

Uma segunda série de tabulações foi compilada a respeito de adolescentes bem jovens (com idade entre 10 e 14 anos), em resposta ao aumento do interesse em se saber mais sobre este subgrupo.

"Dados Selecionados de DHS sobre jovens de 10 a 14 anos" abrange muitas das dimensões mencionadas acima (residência, condições de moradia, escolaridade), mas concentra-se adicionalmente em:

- Mapeamento de garotas e rapazes por condições de moradia e matrícula escolar, visando observar que proporção não dispõe de estruturas de proteção de pais e da escola

- A relação entre condições de moradia e matrícula escolar, e como isto varia em função do gênero

- A proporção de garotas que já fez sexo, casou-se ou deu à luz com menos de 15 anos

- Exposição a rádio e televisão (urbana/rural)

Consulte http://www.popcouncil.org/gfd/gfddhs.html para obter mais informações.

A equipe do Population Council, motivada pela avaliação anterior do alcance das organizações de atendimento à juventude, desenvolveu esta ferramenta e aplicou-a a programas direcionados aos jovens na Etiópia (2004), Burkina Faso (2005), Mauritânia (2005) e Guiné Bissau (2006). O EC permite que os prestadores e organizadores de serviços percebam a diversidade interna da população que atendem, e identifiquem a proporção de jovens divididos por subgrupos: idade, gênero, escolaridade, estado civil, e condições de moradia (e outras categorias relevantes). Abaixo há dois diagramas básicos que podem ser gerados por organizações que coletam dados durante um EC. Estes dados podem ser utilizados para fornecer comentários quanto a seus programas estarem ou não 
atingindo, naquele momento, as populações que pretendem alcançar. Estes dados podem ser empregados para se traçar um perfil das pessoas que estão sendo atualmente atingidas por seus programas, em comparação com as que se tem a intenção de alcançar.

Tabela 1. Distribuição de adolescentes de acordo com a idade e gênero por escolaridade

\begin{tabular}{|l|c|c|c|}
\hline \multirow{2}{*}{ Idade e gênero } & \multicolumn{2}{|l|}{ Escolaridade } \\
\cline { 2 - 4 } & $\begin{array}{l}\text { Freqüentando } \\
\text { escola primária }\end{array}$ & $\begin{array}{l}\text { Freqüentando } \\
\text { escola secundária }\end{array}$ & Fora da escola \\
\hline Garotas 10-14 a. & A & B & C \\
\hline Garotas 15-19 a. & D & E & F \\
\hline Rapazes 10-14 a. & G & H & L \\
\hline Rapazes 15-19 a. & J & K & \\
\hline
\end{tabular}

Tabela 2. Distribuição de adolescentes de acordo com idade e gênero por estado civil e condições de moradia

\begin{tabular}{|l|c|c|c|c|}
\hline & \multicolumn{2}{|l|}{ Estado civil } & \multicolumn{2}{l|}{ Condição de moradia } \\
\cline { 2 - 5 } Idade e gênero & $\begin{array}{l}\text { Casado com } \\
\text { ou sem filhos }\end{array}$ & $\begin{array}{l}\text { Não casado } \\
\text { com ou sem } \\
\text { filhos }\end{array}$ & $\begin{array}{l}\text { Morando com } \\
\text { ambos os pais }\end{array}$ & $\begin{array}{l}\text { Morando com } \\
\text { um ou nenhum } \\
\text { dos pais }\end{array}$ \\
\hline Garotas 10-14 & A & B & A & B \\
\hline Garotas 15-19 & C & D & C & F \\
\hline Rapazes 10-14 & E & F & E & H \\
\hline Rapazes 15-19 & G & H & G & \\
\hline
\end{tabular}

Fonte: Adaptado da tabela (p. 41) em "Etapas na construção de programas baseados em evidências para adolescentes," (Judith Bruce), Capítulo 2 do Instruções Norteadoras para uma Segunda Geração de Programas de Ação, documento de base para a oficina do UNFPA/Population Council sobre Saúde Sexual e Reprodutiva de Adolescentes e Jovens: Instruções Norteadoras para uma Segunda Geração de Programas para Adolescentes, Nova York, 1-3 Maio de 2002.

Com os dados assim gerados por meio de EC, as organizações podem decidir se os objetivos de seus programas estão sendo cumpridos e/ou se desejam alterar sua abordagem e alcance de modo a atender um grupo diferente de adolescentes e/ou oferecer outros serviços às pessoas que já são atendidas por eles. 
Um exercício de cobertura, quando implantado pela primeira vez junto a uma organização, fornece uma avaliação rápida de corte transversal ao mesmo tempo em que também estabelece uma linha de base para monitoramento futuro. Um dos recursos mais notáveis dos ECs está no fato de que os dados são coletados por aqueles que têm interação face-aface com os beneficiários dos programas. Isto significa, por exemplo, que um programa de educação de pares utilizaria seus multiplicadores para coletar os dados. Além disso, os dados são coletados no transcurso normal do trabalho, o que faz com que a coleta de dados não exija recursos financeiros para ser realizada. Torna-se necessário haver apenas um formulário para a coleta de dados, também conhecido como registro de atividade (ver Anexos A.1, A.2, B.1, B.3, B.4 e B.5), uma caneta e alguma coisa sobre a qual se possa escrever. Software de análise estatística pode agilizar o processo de tabulação depois dos dados terem sido colhidos, mas os dados também podem ser tabulados manualmente (ver Anexo A.1). ${ }^{2}$

\section{Benefícios de um exercício de cobertura:}

- Permite que gestores de programas e prestadores de serviços (tais como educadores de pares ou funcionários de centros de juventude) saibam quem eles estão atingindo

- Funciona como uma ferramenta tanto de monitoramento quanto de avaliação

- Desenvolve capacidade futura de monitoramento e avaliação de programas

- Facilidade de utilização (não requer nível elevado de alfabetização ou habilidades sofisticadas de análise de dados)

- Supõe técnicas simples e replicáveis

- Baixo custo

- Permite ter em mãos a propriedade dos dados

- Utiliza as pessoas que já prestam serviços na coleta de dados como parte da rotina normal de trabalho

- Possibilita um mecanismo de feedback para profissionais que raramente dispõem deste tipo de recurso

\footnotetext{
2 Em algum momento, um exercício paralelo ao de cobertura deve ser realizado para se fazer o inventário do conteúdo dos programas oferecidos por órgãos governamentais e organizações não-governamentais. O Anexo A.2 é um exemplo do tipo de ferramenta que se pode utilizar para ajudar a determinar qual "pontos de entrada" programáticos (saúde, educação, trabalho, etc.) estão exigindo o grosso da atenção e dos recursos programáticos. Esta ferramenta será amplamente indicativa, servindo como guia muito geral a auxiliar a identificar a negligência em assuntos bem como em subconjuntos da juventude.
} 


\section{Quem pode beneficiar-se de um exercício de cobertura?}

Muitos interessados podem beneficiar-se de um exercício. Estes abrangem mas não se limitam aos seguintes:

- organizações individuais prestadoras de serviços

- um grupo ou comunidade de organizações que atendam a uma clientela comum

- um grupo ou comunidade de organizações que atuem numa determinada área de captação (cidade, região, país)

- planejadores de programas

- doadores (patrocinadores)

Organizações individuais que desejem compreender quem elas estão atingindo deveriam realizar um EC. No caso dos serviços direcionados aos jovens, poder-se-ia tratar de programas de educação de pares, programas que se concentram numa atividade específica, tais como futebol ou meios de subsistência e/ou organizações religiosas.

Uma comunidade de organizações que atendam a uma clientela comum que desejem saber quem está sendo "captado" pelos programas, em contraposição a quem está sendo deixado de lado, também deveria realizar um EC. Uma organização está atingindo mais garotas do que rapazes? Quais estratégias podem permitir que esta organização atinja mais jovens quando outras estão alcançando menos? Problemas comuns poderão ser identificados possibilitando a discussão e o entrosamento entre instituições distintas.

Uma comunidade de organizações, dentro de uma determinada área de captação, que deseje entender o acesso diferencial aos serviços naquela região também deve realizar um EC. Quais populações estão sendo atingidas nesta região? Algumas populações não estão sendo alcançadas de forma alguma? Há uma diferença no perfil dos serviços recebidos em função da idade, gênero e características sociais?

Planejadores de programas devem iniciar a implantação de um EC de modo a ajudar a identificar as lacunas programáticas ou a aumentar o alcance dos programas que estão cumprindo de forma bem sucedida as suas metas.

Doadores (patrocinadores) devem utilizar os ECs para saber de que maneira o financiamento de programas está sendo utilizado, quem está sendo atingido por meio dos 


\section{(1) Population Council}

investimentos e com que tipos de serviços e alcance. Os resultados de um EC ajudam os doadores e patrocinadores a identificar necessidades e a direcionar futuros investimentos.

\section{Quanto custa um exercício de cobertura?}

As principais despesas de um exercício de cobertura realizado pela primeira vez são oficinas de treinamento (que incluem deslocamento e diárias dos participantes), criação e fotocópias das ferramentas de coleta de dados, recursos humanos para gerenciar e analisar os dados e oficinas de multiplicação/divulgação.

A experiência de condução de exercícios de cobertura em quatro diferentes países africanos fornece uma base para a estimativa de custos. Supondo-se a participação de entre 13 e 20 organizações, os custos locais diretos ficam abaixo de US\$10.000. Na Etiópia, 6 semanas de coleta de dados por parte de 13 das principais organizações de atendimento à juventude custaram US\$7.000. Em Burkina Faso, 20 organizações que coletaram dados durante 6 semanas em locais urbanos e rurais tiveram um custo inferior a US\$15,000. Os custos de cooperação técnica externa para as quatro localidades até o momento giraram entre US\$10.000 e US\$15.000 por localidade. Portanto, se forem incluídos todos os custos diretos, um exercício de cobertura envolvendo de 13 a 20 organizações poderá e geralmente irá custar menos do que US\$25.000.

Se uma organização comunitária (OC) tiver que realizar um exercício de cobertura por conta própria, sem contratar assistência de pesquisa, e optando por não compartilhar os resultados com outras entidades, os custos de um exercício de cobertura poderiam ser nominais - seria o custo das ferramentas de coleta de dados e tempo dedicado pela equipe para tabular os dados. ${ }^{3}$

\footnotetext{
${ }^{3}$ A ferramenta de coleta de dados original (ver Anexo A.1) surgiu pela primeira vez nas "Etapas na Construção de Programas Baseados em Evidências para Adolescentes" (Bruce, 2003). É a forma mais simples que uma organização poderia utilizar e esta permite a ocorrência de tabulações manuais.
} 


\section{Como se realiza um exercício de cobertura?}

Um exercício de cobertura é realizado em 5 fases principais durante aproximadamente 7 meses:

1. Seleção de parceiros e definição de um formato e quadro de referências comum (4 semanas)

2. Sensibilização da equipe e planejamento geral (4 semanas)

3. Realização do treinamento e da coleta de dados (4-6 semanas)

4. Digitação e análise dos dados (4-6 semanas)

5. Divulgação de dados em seminário e diálogo inicial com as organizações participantes, doadores e patrocinadores e gestores de programas e políticas (1-2 dias para divulgação)

Tanto a realização de um exercício de cobertura num local central, como no caso de um centro de juventude quanto num programa de amplo alcance, tal como no caso de um programa de educação de pares seguem estas mesmas fases. Devemos recordar que é possível, e freqüentemente desejável, realizar tanto um exercício de cobertura de um programa de educação de pares quanto de um centro de juventude ao mesmo tempo. Por exemplo, se um centro de juventude oferece uma variedade de atividades, entre elas educação de pares, então é possível abrigar um exercício de cobertura de educação de pares num estudo mais amplo de um centro de juventude. Enquanto uma equipe concentrase na utilização geral dos programas do centro de juventude, os educadores de pares podem coletar dados sobre atividades voltadas à ampliação do alcance. A observação atenta de ambos os tipos de atividades permite-nos obter uma compreensão muito abrangente do escopo dos serviços oferecidos num dado centro de juventude ou por programa voltado ao atendimento de jovens.

\section{Fase 1. Seleção de parceiros e definição de um formato e quadro de referências comum}

\section{- Tempo estimado: 4 semanas}

- Atividades principais a serem realizadas:

- Identificação das organizações que realizarão o exercício

- Coleta de informações de fundo sobre os programas/organizações a serem estudados

A palavra-chave nesta etapa é a flexibilidade. Os parceiros irão variar de acordo com a política, com o doador/patrocinador e outras necessidades dentro de um mesmo país ou região. Em alguns lugares, existem consórcios preexistentes de organizações de 


\section{(1) Population Council}

atendimento à juventude que podem constituir-se numa base. Por exemplo, na Etiópia, a PACT (uma organização guarda-chuva que presta apoio técnico a uma rede de ONGs) colaborou com o Population Council e com o Ministério de Juventude. Em Burkina Faso, na Mauritânia e na Guiné Bissau, as equipes da UNFPA e do Population Council identificaram serviços de atendimento aos jovens; uma elevada proporção de tais organizações que foram contatadas tinha a intenção de participar da coleta de informações. Em alguns cenários, os doadores ou patrocinadores poderão ter um interesse particularmente forte nestas avaliações na medida em que desejem tomar decisões baseadas nas evidências a respeito de como direcionar recursos aos jovens de modo a atingir os mais necessitados.

Concluída a escolha dos parceiros e das pessoas de contato, os interessados precisam especificar suas metas. Todo e qualquer dos itens indicados a seguir podem ser escolhidos. Os interessados desejam identificar:

- Quem está sendo atingido por um programa ou organização específica?

- Quais subgrupos estão sendo alcançados por uma comunidade de organizações com uma clientela comum?

- Quem dentro de uma área geográfica e para uma população específica, tais como adolescentes de 10 a 14 anos, estão sendo atingido por todos os programas?

- Quem está sendo atingido por programas financiados por um doador/patrocinados específico?

Um EC pode ser utilizado para definir o perfil dos beneficiários de um único programa, de um grupo de programas numa mesma organização, de uma determinada área de captação, em todo o universo de organizações de atendimento à juventude, numa dada região ou a cobertura de projetos nacionais. Na Mauritânia, em Burkina Faso e na Guiné Bissau, o UNFPA estava empenhado em obter dados de cobertura com representatividade nacional. A opção pela cobertura nacional significa acesso em larga escala a um número de instituições e a resultados de atendimento juvenil que possam contribuir para orientar decisões de políticas mais amplas bem como a alterações no nível dos programas. Outra opção é concentrar um EC numa única organização. Por exemplo, se uma agência de cooperação estiver cogitando estabelecer uma parceria com o maior programa de educação de pares em Yaoundé a fim de fornecer informações de saúde a garotas de meio urbano que esteja fora da escola, com idade entre 15 e 19 anos, ela poderia utilizar o EC para determinar a qualidade com que o programa, num dado momento, presta aqueles serviços. 
Com o intuito de coletar informações sobre populações que estão sendo atingidas por mais de uma organização, é importante que a equipe que realiza o EC identifique primeiramente as principais organizações que trabalham para atingir a população alvo e, em seguida, selecione um grupo representativo destas organizações. Organizações que participam de EC multi-local sempre têm a opção de contribuir com dados brutos para um esforço maior ao mesmo tempo em que preservam seu anonimato - as análises podem ser igualmente instrutivas sem que estejam amarradas a programas específicos.

Uma vez determinado qual ou quais programas estarão participando, é importante decidir quem realizará a coleta de dados. Uma alternativa é fazer com que todos os educadores de pares (multiplicadores) ou outros prestadores de serviços do(s) programa(s) participem. Outra opção é tomar uma amostra representativa dos prestadores de serviço participantes — prestando particular atenção a características tais como idade, gênero e escolaridade. Caso um programa tenha 10 educadores de pares e haja 5 rapazes e 5 garotas, poder-se-ia decidir em ter 2 de cada para participar. Se um programa tivesse 8 garotas e 2 rapazes, a decisão poderia ser ter 4 garotas e 1 rapaz na coleta. Poderá ocorrer que os educadores de pares mais atuantes ou outros prestadores de serviço sejam selecionados para participar em função de seu envolvimento com o programa. Esta alternativa é boa, contanto que as tabulações sejam interpretadas tendo-se isso em mente. Um dos primeiros passos neste estágio, portanto, é o de coletar informações sobre as características dos próprios educadores de pares ou de outros prestadores de serviço (no Anexo B.1 encontra-se um exemplo de formulário). Uma vez decidido quem coletará os dados, é importante pensar a respeito dos prazos; deve-se decidir por uma duração apropriada (algo entre 1 e 12 semanas) para o período de coleta de dados de modo que esta representará com precisão o ano inteiro.

\section{Fase 2. Sensibilização da equipe e planejamento geral}

\section{- Tempo estimado: 4 semanas}

\section{- Principais atividades realizadas:}

- engajamento da(s) organização(ões) participante(s)

- seleção da equipe (específica para o EC)

- finalização da ferramenta de coleta de dados

- elaboração da oficina de treinamento

- definição de um cronograma para o EC 
O primeiro passo da fase 2 é identificar a pessoa responsável pelo gerenciamento geral do EC (ou o coordenador do projeto), bem como o elo de ligação com cada organização ou programa participante. Estabelecer um terreno comum e uma compreensão mutua das metas do projeto é algo essencial neste momento. Nos casos em que uma única organização esteja conduzindo um EC, este estágio será simplificado devido à presença de um gerente de programa, membro do quadro funcional ou um prestador de serviço ou educador de pares, altamente motivado para atuar como coordenador do projeto.

Uma vez que os principais parceiros cheguem a um acordo quanto aos objetivos, o coordenador do projeto deve informar às organizações comunitárias (OCs) a respeito do exercício de cobertura que está sendo realizado e convidá-los a participar. Tipicamente, o coordenador explica que sua agência está patrocinando uma atividade de capacitação que produzirá informações úteis a respeito dos beneficiários do(s) programa(s). Não há custo para a organização. Tudo o que está sendo solicitado é que is eles enviem todos ou um subgrupo representativo de educadores de pares ou outros prestadores de serviço para um treinamento e que estejam dispostos a coletar dados além de suas outras responsabilidades durante o período de realização do estudo (quatro a seis semanas). Um a dois meses depois do término da coleta de dados, serão convidados novamente para uma outra reunião em que ficarão sabendo dos resultados obtidos pelo estudo e serão solicitados a apresentarem seu feedback e os dados colhidos.

Caso um programa seja convidado a participar e seus gestores se recusem - seja porque acham que seus funcionários já estão sobrecarregados ou serão avaliados pelo EC - seja por algum outro motivo - o coordenador do programa deve considerar a hipótese de convidar os gestores para a oficina de divulgação. Isto lhes proporcionará a oportunidade de avaliar por si próprios a utilidade do exercício de cobertura.

Nos casos em que uma organização comunitária $(\mathrm{OC})$ estiver executando um exercício de cobertura por conta própria, poderá ser desejável treinar todos os educadores de pares disponíveis para coletar informações ao invés de selecionar apenas alguns. Nesta situação, um administrador ou gerente de programa provavelmente atuaria no papel de coordenador, talvez em parceria com uma agência de assistência técnica no caso da primeira implantação, e o EC produziria informações tanto sobre o estado geral do programa quanto das conquistas em nível individual entre os educadores de pares. 0 resultado seria, com efeito, uma auto-avaliação de cada educador de pares bem como a base de um sistema de informações de gestão (SIG). Uma vez que a organização comunitária 
tenha concluído um único EC, estará em condições de prosseguir, de forma rotineira, com a coleta e análise de dados sobre os serviços.

\section{Benefícios que uma organização tem por participar de um exercício de cobertura \\ - capacita-se tanto no nível individual quanto no institucional \\ - equipes de programa, em geral, vêem os treinamentos com bons olhos e os consideram úteis \\ - $\quad$ permite fazer uma auto-avaliação aos que mantêm contato face a face com os beneficiários de programas \\ - fornece os fundamentos de um sistema de informações de gestão ao nível do programa \\ - $\quad$ permite que uma organização perceba quem está sendo atingido por ela e por meio de quais serviços}

\section{Por que as organizações podem hesitar em participar}

- os gestores poderão achar que estão sendo avaliados

- preocupação de que as equipes de trabalho já estejam sobrecarregadas

O coordenador deve entrar em contato com as agências participantes, com alguns dias de antecedência à oficina, a fim de confirmar se os educadores de pares ou prestadores de serviço têm a intenção de comparecer à mesma.

Ao mesmo tempo, a equipe deverá identificar:

- Um coordenador de análise que saiba como utilizar software estatístico; nos casos em que haja somente uma organização participando do EC, o coordenador de análise deverá saber como gerar tabulações e cruzamentos simples, seja utilizando pacotes estatísticos seja manualmente, para realizar as análises dos dados. Tempo estimado de trabalho total: um mês

- Um assistente de projeto para cada cinco organizações participantes. Idealmente, os assistentes devem ser fluentes nos idiomas falados nas áreas onde ocorrerá a coleta de dados. (Opcional, mas desejável.) Tempo estimado de trabalho total: três semanas

- Dois a três assistentes para digitação de dados que farão o trabalho de digitação e limpeza dos dados (podem ser também os coordenadores de análise). Tempo estimado de trabalho total: três a cinco semanas, dependendo da quantidade de dados esperada 
- Um instrutor para ministrar a oficina de treinamento - idealmente, trata-se da mesma pessoa que realiza a função de assistente do projeto. Tempo estimado de trabalho total: três dias (dois dias de elaboração, um dia de oficina)

Quando os ECs são realizados por uma agência de assistência técnica, estas fornecem um coordenador de análise, os assistentes de projeto bem como a digitação dos dados como parte do seu apoio. Nas situações em que organizações comunitárias assumem um EC por conta própria, poderá ser utilizada a equipe já existente ou poderá ser necessário contratar consultores para desempenharem estas funções.

Os centros de juventude talvez necessitem de pessoal extra, já que tipicamente são locais dotados de espaços comuns tanto internos quanto externos. Centros de juventude populares podem atrair centenas de adolescentes por dia. Ao mesmo tempo, os centros de atenção juvenis tendem a ter poucos funcionários. Poderá haver um gestor do centro de juventude e funcionários adicionais em número suficiente (às vezes remunerados, às vezes voluntários) para propiciar uma presença de adultos em meio a todos aqueles jovens. Esta combinação de fatores faz com que a coleta de dados seja ligeiramente mais desafiadora para o centro de juventude se comparada aos educadores de pares. Uma maneira de otimizar o número de pessoas atendidas num centro de juventude a serem introduzidas num registro de dados é posicionar um funcionário na saída do centro. Esta pessoa poderá então adicionar pessoas ao registro cada vez que estas saem do centro durante o período do estudo. Isto talvez não seja possível de se realizar, contudo, em função de haver freqüentemente poucos funcionários num centro de juventude. Outra abordagem, portanto, é contratar um ou dois assistentes de projeto por centro de juventude e acomodá-los numa saída para que registrem os jovens quando estes saírem do local. Dependendo da abordagem que será utilizada, a fase de planejamento poderá exigir a contratação e treinamento de assistentes de projeto. Todas as pessoas que tenham sido designadas para realizar a coleta de dados deverão comparecer à oficina de treinamento.

\section{Finalização da ferramenta de coleta de dados (o registro de atividades)}

Uma vez montada a equipe de pesquisa, é hora de preparar a oficina de treinamento. Uma etapa essencial é o trabalho em cima dos formulários de coleta de dados (os registros de atividades) em colaboração com os educadores de pares, outros prestadores de serviço e/ou gestores. Para os que desejem utilizar o formulário mais ágil e simples desta ferramenta, pede-se que consultem o Anexo A.1. Este formulário mais simples presta-se a 
cálculos manuais, sendo mais comparável a um registrado de horário de entrada/horário de saída. Para começar o processo de coleta de dados, fornecemos um formulário para a coleta de informações a respeito dos próprios educadores de pares (Anexo B.1) e um questionário para as organizações preencherem logo de início (Anexo B.2). No Anexo B.3, fornecemos uma amostra de registro de atividades a ser utilizado pelos educadores de pares em suas atividades com usuários individualmente (com base naquele utilizado no EC realizado na Etiópia), ao passo que o Anexo B.4 mostra um exemplo de um registro de atividades em grupo a ser utilizado por educadores de pares em suas atividades grupais (também baseado no EC conduzido na Etiópia). No Anexo B.5, fornecemos um exemplo de registro de atividades a ser empregado na entrada ou saída de um centro de juventude (com base naquele utilizado na Mauritânia). Em alguns casos, será útil realizar uma reunião prévia à oficina, talvez uma semana ou mesmo um dia antes do treinamento, para discutir o formulário de coleta de dados e fazer ajustes, tomando em conta o contexto local. Será importante considerar o cronograma (com relação a férias escolares, feriados, eventos especiais, etc.) e a extensão (duração) do período de coleta. Dependendo do contexto, da verba disponível e da avaliação da variação ao longo do período de tempo, a duração da coleta de dados poderá variar (estendendo-se de 1 a 12 semanas). Se se estiver tentando capturar uma "fotografia" dos serviços oferecidos, pode ser que se queira coletar dados por apenas 1 ou 2 semanas; caso se esteja tentando obter um quadro abrangente e completo, poderá ser útil coletar as informações por um período mais longo de tempo a fim de conseguir dados mais precisos.

Embora os elementos básicos do formulário permaneçam constantes de um cenário a outro, é importante certificar-se de que os termos utilizados sejam adequados à realidade local. Por exemplo, poderá ser necessário alterar a categoria estado civil, em função do contexto; termos tais como 'morar junto com alguém' ou 'relacionamento de longo prazo' ao invés de 'solteiro' ou 'casado' poderá melhor refletir o contexto social em alguns cenários. É essencial que os formulários reflitam o real escopo de trabalho dos educadores de pares e outros prestadores de serviço. Adicionalmente aos simples registros de atividades, os formulários destinados a coletar informações sobre os próprios educadores de pares (Anexo B.1) e sobre as organizações (Anexo B.2) serão úteis no fornecimento de informações contextuais. Certifique-se de que o educador de pares preencha seu nome e o da organização para a qual trabalha de modo que os responsáveis pela coleta de dados possam vincular os educadores de pares apropriados às organizações corretas e a seus registros de atividades. Lembre-se que o que se quer ver é se os rapazes conversam com rapazes, se as garotas conversam com garotas e assim por diante. 


\section{Population Council}

\section{Elaboração da oficina de treinamento}

A programação utilizada no treinamento em Burkina Faso encontra-se anexada (consulte o Anexo C). Além do desenvolvimento de uma programação, é importante reunir suprimentos de pesquisa e fazer cópias dos registros de atividades. Depois da oficina, os educadores de pares e outros prestadores de serviços retornarão às suas comunidades e estarão prontos para iniciar a coleta de dados. Isto significa que eles sairão da oficina com tudo o que necessitam para realizar esta tarefa. Isto abrange:

- Formulários de coleta de dados em número suficiente para durar por todo o período do estudo. Em Burkina Faso, cada educador de pares recebeu formulários suficientes para registrar até 300 contatos. Este suprimento foi suficiente, mas em outros contextos, talvez não fosse o bastante. Os educadores de pares não necessariamente saberão a quantidade de beneficiários com os quais eles entrarão em contato no transcurso de um mês (uma das razões para se realizar um EC é saber exatamente esta cifra), assim deve-se buscar um equilíbrio entre dar aos educadores de pares um kit de coleta de dados que não seja muito pesado de se carregar e um que irá durar por todo o período da coleta de dados. Em Burkina Faso, cada pessoa recebeu 60 registros de atividades referentes a informações individuais (Anexo B.3) e 20 registros de atividades em grupo (Anexo B.4). Quando os assistentes de projeto fizeram visitas a campo, levaram formulários extras consigo para repor os suprimentos conforme as necessidades.

- Canetas com as quais serão preenchidos os formulários.

- Materiais suplementares (uma lista de códigos caso não constem dos próprios formulários, uma lista de informações de contato para a equipe).

- Pastas para guardar estes materiais e facilitar o seu transporte.

\section{Elaboração de um cronograma}

A equipe deve desenvolver um cronograma para o exercício de cobertura, começando pelo treinamento e seguindo até a Fase 3 (ver abaixo).

A equipe também deve decidir de que maneira irá recolher os formulários de coleta de dados ao final do exercício de cobertura. Os educadores de pares e outros prestadores de serviço podem ter se deslocado de distantes regiões rurais até a capital para receber o treinamento, mas é provavelmente irrealista em termos tanto de tempo quanto de despesas trazê-los de volta ao final do período de coleta para entregar pessoalmente seus formulários ao gerente do programa. Onde for possível, o ideal será certamente fazer com que os educadores de pares retornem pessoalmente seus registros de atividades preenchidos, ou façam com que um educador de pares de cada região recolha os registros do grupo e se 
desloque para devolver os formulários. Nos casos em que não for possível, outras opções devem ser discutidas antes de levar o EC a campo. Em alguns contextos, será mais prático ou eficiente que um dos assistentes do projeto viaje de um lugar a outro para recolher os formulários. Algumas localidades dispõem de sistemas de mensageiros informais - isto funcionou bem em Burkina Faso. No fim das contas, os parceiros locais terão o melhor juízo sobre como transportar os dados de maneira eficiente e segura das áreas rurais para os níveis centrais.

\section{Fase 3. Realização do treinamento e início da coleta de dados}

- Tempo estimado: 4 a 6 semanas (pode levar mais tempo se o período de coleta de dados chegar a 12 semanas)

- Atividades principais a serem realizadas:

- treinamento dos educadores de pares ou outros prestadores de serviço para a coleta de informações sobre suas atividades e com as pessoas com as quais eles têm contato

- assistentes de projeto a postos para dar suporte à coleta de dados

- recolhimento dos formulários preenchidos

- desenvolvimento das telas para digitação dos dados

\section{Oficina de treinamento}

A oficina de treinamento requer um dia (em lugares com limitação de acesso, poderá ser necessário planejar um dia a mais já que os participantes talvez gastem um dia de viagem se deslocando para chegarem à oficina). Tipicamente, o coordenador apresenta as justificativas que fundamentam a realização do EC, e em seguida o instrutor ensina aos educadores de pares ou outros prestadores de serviço que participam do treinamento como utilizar o formulário de coleta de dados. O instrutor explica, coluna por coluna, o que deve ser preenchido e as diferentes opções para as questões a serem feitas durante o trabalho de campo. O instrutor repassa e analisa as diretrizes relativas à confidencialidade (não é necessário anotar o nome de ninguém) e a finalidade da avaliação do programa, inclusive o modo como os dados serão utilizados. Há bastante tempo para perguntas e respostas e de interação entre o instrutor e os participantes. Após uma explicação inicial, os educadores de pares ou outros prestadores de serviços encenam uma simulação de aplicação do formulário a fim de praticarem a coleta de informações. O instrutor e os assistentes de projeto circulam pela sala para trabalhar com pequenos grupos e indivíduos, certificando-se de que todos compreendam a maneira de utilizar o formulário e como fazer as perguntas. 


\section{Population Council}

Uma vez que tenham dominado estas habilidades (deve-se reservar até uma hora para isto), é apresentado um segundo formulário: este captura as mesmas informações, sendo desenvolvido para facilitar a coleta de dados em grandes grupos. Novamente, o instrutor explica como preencher o formulário e, em seguida, os educadores de pares ou outros prestadores de serviço praticam esta tarefa entre si. O instrutor enfatiza os seguintes pontos:

- Preencher o formulário para toda e qualquer pessoa com a qual haja interação no desempenho da sua função como educador de pares (multiplicador) ou prestador de serviço, mesmo que aquela pessoa seja mais velha ou mais jovem que o grupo etário alvo e mesmo que o encontro se dê numa situação de grupo.

- Não é necessário anotar o nome da pessoa - todos os dados coletados são confidenciais, mas precisa-se escrever NA no começo da linha e pular para a próxima linha para um novo contato.

- Se alguém não quiser ter seus dados registrados no registro de atividades, tem o direito de não responder.

- Na lista de atividades, é essencial relacionar tudo que se aplique a uma entrevista/contato em particular - não há problemas se forem dadas múltiplas respostas (estas devem ser registradas); o mesmo vale para os assuntos abrangidos. (Isto requer prática extra durante a encenação que simula a aplicação do formulário.)

- Os registros de atividades devem ser sempre preenchidos com caneta.

- $\quad$ O registro deve registrar usuários que são contatados mais de uma vez e registrar todos os contatos com elas, mesmo que elas sejam contatadas todos os dias. Esta informação é muito valiosa!

- Não devem planejar atividades especiais durante o período de coleta de dados devem realizar as tarefas como o fazem normalmente.

- Somente eles devem adicionar nomes aos registro; caso estejam realizando uma sessão em grupo, podem fazer com que um assistente circule pelo local para completar o registro da atividade em grupo.

- Devem portar suas pastas com registros de atividades consigo em todos os lugares durante o período do estudo.

- Devem fazer perguntas após terem tido uma interação com um dos pares. A série de perguntas é curta e não deve levar mais do que dois minutos para ser respondida. No treinamento, é importante insistir no fato de que esta atividade não deve perturbar sua função de educador de pares ou como outro prestador de serviço. E esta atividade de preenchimento do questionário não deve prejudicar a qualidade das relações atuais e futuras com aquele par.

- Durante o treinamento, é útil lembrar aos educadores de pares que este exercício Ihes é valioso porque lhes permite manter um controle de todas as interações que 


\section{Population Council}

eles tiveram durante o mês. É como tirar uma fotografia do que está acontecendo de fato, do que fazem realmente sendo uma oportunidade única para que eles permitam que outras pessoas conheçam o trabalho que desenvolvem.

- Durante toda a oficina, o instrutor deve reservar tempo para perguntas e comentários sobre os formulários a fim de certificar-se de que todos compreendam o exercício bem como incentivem a participação e abertura para compartilhar comentários. Por exemplo, alguns educadores de pares poderão estar se perguntando em relação ao entendimento de uma questão por parte de do par. $\mathrm{O}$ instrutor deve explicar todas as questões e as respostas possíveis a cada uma delas. Antes do final da oficina de treinamento, o instrutor deve certificar-se de que não haja perguntas pendentes e que os participantes tenham dominado o preenchimento do formulário antes de partir para o campo.

- O instrutor deve fornecer uma frase de apresentação no guia de instruções do EC aos educadores de pares ou outros prestadores de serviço de modo que eles possam explicar brevemente a finalidade das perguntas que serão feitas ao par. Eles então lerão a frase antes de preencher o registro de atividade diante do par. Eis um exemplo de frase para este fim: "Será que você se importaria se eu fizer a você algumas perguntas? Estou fazendo um relatório de todos os contatos que eu tenho com meus pares para que a organização conheça melhor o trabalho que estou fazendo. Os educadores de pares (multiplicadores) estão fazendo isso em todo o país este mês. Você não precisa me dizer o seu nome."

Os educadores de pares ou outros prestadores de serviço saem da oficina com todos os materiais e informações de que necessitam, inclusive os contatos dos assistentes do projeto (se houver). Eles são instruídos a começar a coleta de dados assim que retornarem às suas casas e retomem suas atividades, e a ligar ao coordenador do projeto caso tenham quaisquer dúvidas. Em alguns cenários, caso o orçamento do EC permita, poderá ser interessante fornecer aos educadores de pares um cartão de telefone.

\section{De que maneira os assistentes do projeto podem prestar suporte aos educadores de pares ou outros prestadores de serviço}

Algumas palavras sobre os assistentes de projeto e sobre a decisão a respeito de contar com eles ou não: A função dos assistentes de projeto durante a fase de coleta de dados é prestar suporte aos educadores de pares ou outros prestadores de serviço que estejam colhendo dados. Eles realizam esta tarefa colocando-se à disposição através de contato por telefone ou pessoalmente. Isto ajuda os educadores de pares a lidar com as diferentes situações com as quais se defrontam no campo ou os ajuda caso estes fiquem sem formulários. Os assistentes de projeto não são necessários mas com certeza contribuem para a obtenção de dados de qualidade. Caso os gestores de programas tenham comparecido à oficina de treinamento, estes poderão dar suporte aos educadores de pares no lugar dos assistentes de projeto. Dependendo do contexto, um sistema centralizado de 
apoio poderá ser desnecessário. Por exemplo, se uma organização inteira tiver seus educadores de pares participando de um EC, então estes poderão atuar como reforços uns para os outros. Eles teriam contato já estabelecido com um gestor ou com uma equipe de pesquisa.

Quando há a presença de assistentes de projeto, estes podem executar seu trabalho telefonando aos educadores de pares regularmente e/ou fazendo visitas a cada educador de pares pelo menos uma vez durante o período de coleta de dados, deslocando-se por meio de ônibus, trem, outro transporte coletivo ou de carona, e hospedando-se em pousadas simples. Múltiplas localidades são agregadas numa única viagem, de modo que um assistente de projeto possa passar duas semanas no campo indo de um lugar a outro.

\section{Recolhimento dos formulários de dados}

Ao final do período designado para a coleta de dados, os registros de atividades deverão ser enviados - através do método acordado entre as partes - ao coordenador do projeto.

\section{Desenvolvimento de telas para digitação dos dados}

Durante o período de coleta de dados, o coordenador de análise irá elaborar uma tela para a digitação dos dados que facilitará este trabalho posteriormente. Pode-se utilizar programas tais como o Epi Info. Ele ou ela também supervisionará o recolhimento dos formulários de coletas de dados provenientes dos locais do campo e manipulará estes formulários quando chegarem. Esta tarefa inclui fazer um registro para cada formulário que chegue do campo e criar um código que vincule, de forma anônima, um conjunto de formulários a um dado educador de pares e/ou organização. A esta altura, o coordenador treina as pessoas encarregadas de digitar os dados utilizando a tela específica.

\section{Fase 4. Digitação e análise dos dados}

\section{Tempo estimado: 4 a 6 semanas}

- Principais atividades a serem desenvolvidas:

- digitação dos dados no software do computador e posterior análise, ou tabulação manual seguida de análise

- $\quad$ são gerados resultados preliminares na forma de pacotes para discussão 


\section{Population Council}

\section{Digitação e análise dos dados}

O coordenador de análise irá supervisionar a digitação dos dados e a limpeza dos mesmos. Isto significa que será utilizado Epi Info ou algum outro pacote de software estatístico ou será feita a tabulação manual das colunas. Alternativamente, uma organização comunitária poderá escolher um membro de seu quadro ou uma pequena equipe de funcionários para compilar os resultados do EC. A opção por uma abordagem ou por outra dependerá da capacidade da instituição que está executando o EC. O Anexo D inclui uma série de tabelas e figuras que foram geradas a partir exercícios de cobertura anteriores. Os formulários preenchidos devem ser guardados num local seguro até que as análises sejam concluídas e os dados sejam verificados e validados (por até um ano).

A análise deve:

- Ser sempre estratificada por gênero e geralmente também por idade. Uma abordagem seria a utilização de agrupamentos etários de DHS (10-14 anos, 15-19 anos), ou o uso de faixas etárias menores tais como 10-12, 13-15 e 16-19 anos.

- Consultar as tabelas desagregadas de DHS, ou similares, caso estejam disponíveis para o país. (Consulte o website do Population Council, http://www.popcouncil.org/gfd/gfddhs. html, para obter uma lista de países e informações ulteriores, caso se queira dados mais recentes ou análises adicionais em relação a um determinado país, ou ainda para solicitar uma análise para um país que ainda não conste da relação).

- Analisar por organização, por tipo de organização (isto é, organizações financiadas por um determinado doador ou patrocinador), e por localização (urbana/rural) da atividade

- Analisar por estado civil.

- $\quad$ Analisar por escolaridade.

- Analisar por características do educador de pares ou outro prestador de serviço. Responder às perguntas, "As educadoras de pares tendem a falar mais com outras mulheres? Os educadores de pares tendem a falar mais com outros homens? Quais são as idades dos educadores de pares comparadas com as pessoas com as quais eles conversam?"

- Responder às seguintes perguntas:

- $\quad$ "Sobre quantos assuntos os educadores de pares conversam numa interação típica?"

- "Qual é o assunto ou combinação de diversos assuntos que vêm à tona mais freqüentemente nas interações com os educadores de pares? Como variam em função do gênero do par e do educador de pares?"

- "Quais são as características sócio-demográficas dos pares que são atingidos pelos educadores de pares (gênero, idade, nível mais elevado de escolaridade, estado civil, condições de moradia, situação de trabalho)?" 
- "Onde ocorre a interação (no centro de juventude, na clínica, na escola, nos campos, no mercado, no campo de futebol/basquete, numa entidade comunitária ou outro local que deve ser especificado)?"

- "Se a interação acontece durante uma atividade, qual é a natureza desta atividade (discussão em grupo grande /pequeno, discussão individual, pergunta e resposta, esportes, teatro, exibição de vídeo, consultas, distribuição de pílulas, distribuição de preservativos, aconselhamento, tratamento médico)?"

Exemplos de tabelas e figuras que podem ser gerados encontram-se no Anexo D.

Alguns resultados do exercício de cobertura feito na Etiópia
O exercício de cobertura na Etiópia foi conduzido por um período de seis semanas junto a
13 das maiores organizações de atendimento à juventude daquele país. Os resultados
mostram que:
- $\quad$ Os programas atingiam mais os rapazes do que as garotas, sendo quase $60 \%$ dos
contatos com rapazes ou homens.
- Rapazes mais velhos e homens dominavam os programas, sendo $45 \%$ dos contatos
com rapazes de 15 anos de idade ou mais, e 1 de cada 5 eram homens com idade
igual ou superior a 20 anos. $14 \%$ estavam acima da idade desejada de 24 anos.
Os programas estavam atingindo a população mais privilegiada que freqüenta
escola ao passo que a maioria dos adolescentes etíopes está fora da escola.
As informações sobre HIV/AIDS eram mais freqüentemente fornecidas nos serviços
- alcançando $73 \%$ dos rapazes e $64 \%$ das garotas. O conteúdo desta mensagem
pode exigir análises ulteriores na medida em que somente $15 \%$ das garotas e $7 \%$
dos rapazes receberam informações sobre papéis de gênero e somente $23 \%$ dos
rapazes (que tendiam a ser os mais velhos) receberam informações sobre
preservativos.
Somente $3 \%$ dos contatos femininos eram casadas embora a maioria das garotas
da Etiópia se case durante a adolescência e muitas garotas sexualmente ativas
fossem casadas.
Disponível on-line em:
http://www.cih.uib.no/journals/EJHD/eihd19-no1/60.Who\%20are\%20the\%20targets\%20of\%20youth\%20programs.pdf

É notável que, no exemplo da Etiópia mencionado acima, há uma significativa propensão na aplicação dos recursos, direcionados a jovens mais velhos, que freqüentam a escola, geralmente do sexo masculino, e nota-se também que o perfil dos serviços nos centros de juventude está se reorientando de modo concentrar-se primordialmente em HIV/AIDS ao passo que muitos outros tipos de informação (habilidades para a vida, gênero, questões 
relativas a relacionamentos) parecem não estar recebendo muita atenção. Isto também fica patente nos dados provenientes de Burkina Faso que revelam que a maioria das informações recebidas por meio dos contatos era sobre HIV/AIDS (21\% dos rapazes e $16 \%$ das garotas) enquanto outros assuntos, tais como informações sobre habilidades para a vida, recebiam muito menos atenção e foram dadas a apenas $5 \%$ dos rapazes e a $3 \%$ das garotas (Population Council e UNFPA, 2005).

\section{Elaboração de pacotes com resultados preliminares para divulgação}

Uma vez concluída a análise, o coordenador do projeto deve elaborar o esboço de um relatório que seja prontamente compreensível e que seja, idealmente, acompanhado de uma apresentação com apelo visual que será compartilhada com os educadores de pares ou outros prestadores de serviço e gestores de programas, e posteriormente com outros interessados.

A apresentação deve ser utilizada como ponto de partida para a análise, para comprometer os gestores e executores de programas com o processo de reflexão acerca dos seus beneficiários. Esta apresentação deve tentar comparar e contrastar dados nacionalmente representativos de DHS com os resultados obtidos pelo EC. Por exemplo, dados desagregados de DHS no determinado cenário podem mostrar que $78 \%$ das garotas entre 15 e 19 anos não estão na escola. O EC mostra que entre as garotas desta faixa etária, que utilizam um serviço de uma organização comunitária, 78\% estão na escola. Esta comparação ajudaria uma organização comunitária a chegar à conclusão de que ela está atingindo uma pequena e especial parcela de garotas entre 15 e 19 anos, uma vez que a maioria das garotas não freqüentam a escola, mas a maioria das participantes do programa estão na escola. Os resultados também devem ser apresentados no contexto da(s) população(ões) alvo do(s) programa(s).

Durante esta fase, o coordenador do projeto deve agir no sentido de organizar uma oficina de divulgação junto a gestores de programa e aos educadores de pares. 


\section{Fase 5. Divulgação dos dados e reavaliação de programas e políticas em torno da educação de pares}

Tempo estimado: 1a 2 dias para (cada) divulgação; a alteração de programas e políticas será permanente

- Atividades principais a serem realizadas:

- oficina de divulgação junto a educadores de pares, prestadores de serviço e gestores de programas

- oficina de divulgação junto a doadores e patrocinadores, agências governamentais e gestores de políticas públicas

- reestruturação dos programas a fim de melhorar a captação dos grupos subatendidos pelos modelos existentes- ou definição de outros métodos para atingir os que não estão atualmente participando dos programas

Oficina de divulgação junto a educadores de pares, prestadores de serviço e gestores de programas.

Educadores de pares - e outros prestadores de serviço que coletaram os dados - e seus respectivos gestores são os primeiros grupos que deveriam inteirar-se das análises. Os dados tanto de DHS quanto do EC devem ser apresentados de maneira clara e simples para que possa ser compreendido pelo grupo de modo que possam interpretá-los por si próprios. A discussão sobre a realidade que os dados refletem poderá ser dirigida por um facilitador bem como sobre as análises adicionais que sejam justificadas e solicitadas pelas organizações. Devem ser feitas discussões sobre os motivos que levaram àqueles resultados e sobre as estratégias para aprimorar o desempenho dos programas e aumentar a cobertura. Este é também um bom momento para que as equipes dos programas discutam a institucionalização do EC. Elas estarão agora familiarizadas com a situação atual da cobertura de seus programas e poderão decidir as melhores formas de institucionalizar seu uso visando o gerenciamento e o monitoramento de seu trabalho futuro.

\section{Oficina de divulgação com doadores e patrocinadores, agências governamentais, gestores de políticas públicas e outros interessados.}

Com base nas respostas e recomendações feitas pelos educadores de pares e gestores, pode-se elaborar uma apresentação que possa ser compartilhada num segundo encontro de divulgação. Esta reunião seria feita com doadores, patrocinadores e gestores de políticas 


\section{Population Council}

constituindo-se em oportunidade para a proposição de novas maneiras de se atingir os grupos sub-atendidos bem como para informar sobre as deficiências constatadas nos programas existentes. De relevância, os grupos participantes compartilharão o que puderam aprender no processo e as medidas que estão sendo tomadas para o aprimoramento da cobertura e ampliação do alcance rumo às populações sub-atendidas.

Reestruturação dos programas para melhorar a captação dos que são sub-atendidos pelos modelos existentes - ou definição de outros métodos para atingir os que atualmente não estão participando dos programas de multiplicação (educação de pares)

Os resultados obtidos através do exercício de cobertura e as discussões na oficina de divulgação podem ser utilizados para reforçar ou alterar os modelos existentes - ou ajudar a inspirar idéias que conduzam a novos modelos. O momento imediatamente após o exercício de cobertura pode ser propício para explorar mudanças. As idéias ainda estão frescas e a motivação poderá ainda ser elevada.

A presente guia e suas diretrizes fornecem informações bem como ferramentas ilustrativas e resultados provenientes de exercícios de cobertura já realizados. As pessoas interessadas em obter maiores informações poderão entrar em contato com os autores dos estudos anteriores. A experiência até o momento sugere que os prestadores de serviço em todos os níveis - em entidades comunitárias, organizações não governamentais e parceiros de implantação da USAID - podem utilizar esta ferramenta simples para monitorar e avaliar seus programas. O resultado obtido com a coleta de dados auxilia os prestadores de serviço e gestores de programa a compreender se seus programas estão atingindo os beneficiários pretendidos ou não, o que por sua vez ajudar os executores e patrocinadores a concentrar suas atividades e financiamentos para que possam alcançar públicos subatendidos tal como definidos tanto pelo grau de vulnerabilidade quanto pelo peso numérico. 
Anexo A.1: Formulário de Coleta de Dados Desenvolvido para Tabulação Manual

\begin{tabular}{|c|c|c|c|c|c|c|c|c|}
\hline & $\begin{array}{c}\text { Número de } \\
\text { adolescentes em cada } \\
\text { categoria vista nos } \\
\text { últimos } 30 \text { dias }\end{array}$ & $\begin{array}{c}\mathrm{N}^{\mathrm{o}} \text { de jovens de } \\
10 \text { a } 14 \text { anos }\end{array}$ & $\begin{array}{l}\mathrm{N}^{\circ} \text { de jovens de } \\
15 \text { a } 19 \text { anos }\end{array}$ & $\mathrm{N}^{\mathrm{o}}$ de garotas & $\begin{array}{l}\mathrm{N}^{\circ} \mathrm{de} \\
\text { rapazes }\end{array}$ & $\begin{array}{c}\mathrm{N}^{\circ} \text { de adolescentes } \\
\text { na escola }\end{array}$ & $\begin{array}{c}\mathrm{N}^{\mathrm{o}} \text { de } \\
\text { adolescentes } \\
\text { fora da escola }\end{array}$ & $\begin{array}{c}\mathrm{N}^{\mathrm{o}} \mathrm{de} \\
\text { adolescents } \\
\text { casados }\end{array}$ \\
\hline \multicolumn{9}{|l|}{ Garotas } \\
\hline $\begin{array}{l}\text { 1. Garotas não casadas } \\
\text { de } 10 \text { a } 14 \text { anos, na } \\
\text { escola }\end{array}$ & $\mathbf{A}$ & $\mathbf{A}$ & & $\mathbf{A}$ & & $\mathbf{A}$ & & \\
\hline $\begin{array}{l}\text { 2. Garotas não casadas } \\
\text { de } 10 \text { a } 14 \text { anos, fora } \\
\text { da escola }\end{array}$ & B & B & & B & & & $\mathbf{B}$ & \\
\hline $\begin{array}{l}\text { 3. Garotas não casadas } \\
\text { de } 15 \text { a } 19 \text { anos na } \\
\text { escola }\end{array}$ & $\mathbf{C}$ & & $\mathbf{C}$ & $\mathbf{C}$ & & $\mathbf{C}$ & & \\
\hline $\begin{array}{l}\text { 4. Garotas não casadas } \\
\text { de } 15 \text { a } 19 \text { anos fora } \\
\text { da escola }\end{array}$ & D & & D & $\mathbf{D}$ & & & D & \\
\hline $\begin{array}{l}\text { 5. Garotas casadas* } \\
\text { de } 10 \text { a } 14 \text { anos }\end{array}$ & $\mathbf{E}$ & $\mathbf{E}$ & & $\mathbf{E}$ & & & $\mathbf{E}$ & $\mathbf{E}$ \\
\hline $\begin{array}{l}\text { 6. Garotas casadas* } \\
\text { de } 15 \text { a } 19 \text { anos }\end{array}$ & $\mathbf{F}$ & & $\mathbf{F}$ & $\mathbf{F}$ & & & $\mathbf{F}$ & $\mathbf{F}$ \\
\hline \multicolumn{9}{|l|}{ Rapazes } \\
\hline $\begin{array}{l}\text { 7. Rapazes não casados } \\
\text { de } 10 \text { a } 14 \text { anos na } \\
\text { escola }\end{array}$ & $\mathbf{G}$ & $\mathbf{G}$ & & & $\mathbf{G}$ & $\mathbf{G}$ & & \\
\hline $\begin{array}{l}\text { 8. Rapazes não casados } \\
\text { de } 10 \text { a } 14 \text { anos fora da } \\
\text { escola }\end{array}$ & $\mathbf{H}$ & $\mathbf{H}$ & & & $\mathbf{H}$ & & $\mathbf{H}$ & \\
\hline $\begin{array}{l}\text { 9. Rapazes não casados } \\
\text { de } 15 \text { a } 19 \text { anos na } \\
\text { escola }\end{array}$ & I & & $\mathbf{I}$ & & $\mathbf{I}$ & $\mathbf{I}$ & & \\
\hline $\begin{array}{l}\text { 10. Rapazes não } \\
\text { casados de } 15 \text { a } 19 \\
\text { anos fora da escola }\end{array}$ & $\mathbf{J}$ & & $\mathbf{J}$ & & $\mathbf{J}$ & & $\mathbf{J}$ & \\
\hline $\begin{array}{l}\text { 11. Rapazes casados de } \\
15 \text { a } 19 \text { anos** }\end{array}$ & $\mathbf{K}$ & & $\mathbf{K}$ & & $\mathbf{K}$ & & & $\mathbf{K}$ \\
\hline Total: & $\begin{array}{c}\mathrm{A}+\mathrm{B}+\mathrm{C}+\mathrm{D}+\mathrm{E}+\mathrm{F}+\mathrm{G} \\
+\mathrm{H}+\mathrm{I}+\mathrm{J}+\mathrm{K}\end{array}$ & $\mathrm{A}+\mathrm{B}+\mathrm{E}+\mathrm{G}+\mathrm{H}$ & $\mathrm{C}+\mathrm{D}+\mathrm{F}+\mathrm{I}+\mathrm{J}+\mathrm{K}$ & $\begin{array}{c}\mathrm{A}+\mathrm{B}+\mathrm{C}+\mathrm{D}+ \\
\mathrm{E}+\mathrm{F}\end{array}$ & $\begin{array}{c}\mathbf{G + H + I + J +} \\
\mathbf{K}\end{array}$ & $\mathrm{A}+\mathrm{C}+\mathrm{G}+\mathrm{I}$ & $\mathrm{B}+\mathrm{D}+\mathrm{E}+\mathrm{F}+\mathrm{H}+\mathrm{J}$ & $\mathbf{E}+\mathbf{F}+\mathbf{K}$ \\
\hline
\end{tabular}

*Garotas adolescentes casadas raramente são encontradas na escola; portanto, sua escolaridade não é indicada.

**Rapazes de 10 a 14 anos raramente são casados; portanto, não foram incluídos nesta planilha.

Esta ferramenta foi originalmente criada para se chegar às pessoas interessadas; foi executada pela primeira vez por prestadores de serviço em áreas de baixa renda da Cidade de Nova York (em 1973). Naquela época, a tabulação foi feita manualmente pela equipe prestadora de serviço. Os excertos do capítulo dois de Judith Bruce, de 2003 , "Etapas na construção de programas baseados em evidências para adolescentes", esta ferramenta simples pode "[r]eunir e analisar dados sobre adolescentes - agrupados por idade, gênero, estado civil e escolaridade, residência e outras variáveis relevantes - através de uma cuidadosa análise situacional e outras metodologias de pesquisa" (2003; p. 29). 
Q Population Council

Anexo A.2 Planilha: Mapeamento do Conteúdo de Programas de Adolescentes

\begin{tabular}{|c|c|c|c|c|c|c|c|}
\hline $\begin{array}{c}\text { Categorias de Conteúdo de } \\
\text { Programas }\end{array}$ & $\begin{array}{l}\text { Grupo etário } \\
\text { atendido }\end{array}$ & Gênero* & Escolaridade $^{\Delta}$ & $\begin{array}{l}\text { Atividades que } \\
\text { atingem } \\
\text { adolescentes } \\
\text { casados }\end{array}$ & $\begin{array}{l}\text { Número de } \\
\text { atendidos } \\
\text { anualmente }\end{array}$ & \begin{tabular}{|}
$\begin{array}{c}\% \text { do esforço } \\
\text { geral do } \\
\text { programa- } 20 \\
40,60,80,100 \%\end{array} \mid$ \\
\end{tabular} & $\begin{array}{c}\text { Ponto de entrada } \\
\text { principal? }\end{array}$ \\
\hline \multicolumn{8}{|l|}{$\begin{array}{l}\text { Alfabetização funcional e } \\
\text { aprendizagem fora da } \\
\text { escola }\end{array}$} \\
\hline \multicolumn{8}{|l|}{ Nutrição } \\
\hline \multicolumn{8}{|l|}{$\begin{array}{l}\text { Informações sobre saúde } \\
\text { reprodutiva }\end{array}$} \\
\hline \multicolumn{8}{|l|}{ Serviços de saúde } \\
\hline \multicolumn{8}{|l|}{$\begin{array}{l}\text { Treinamento de } \\
\text { habilidades de meios de } \\
\text { subsistência }\end{array}$} \\
\hline \multicolumn{8}{|l|}{$\begin{array}{l}\text { Oportunidades de } \\
\text { poupança / } \\
\text { Alfabetização econômica }\end{array}$} \\
\hline \multicolumn{8}{|l|}{$\begin{array}{l}\text { Oferta de proteção } \\
\text { /segurança a adolescentes } \\
\text { vulneráveis }\end{array}$} \\
\hline \multicolumn{8}{|l|}{$\begin{array}{l}\text { Incentivo à participação } \\
\text { de adolescentes em } \\
\text { processos comunitários e } \\
\text { políticos }\end{array}$} \\
\hline \multicolumn{8}{|l|}{$\begin{array}{l}\text { Oferta de oportunidades } \\
\text { para aumentar a força } \\
\text { física / habilidades } \\
\text { esportivas e em jogos }\end{array}$} \\
\hline \multicolumn{8}{|l|}{$\begin{array}{l}\text { Criação de espaços de } \\
\text { aprendizagem/desenvol- } \\
\text { vimento não familiar, não } \\
\text { escolar para jovens }\end{array}$} \\
\hline $\begin{array}{l}\text { * Exclusivamente ou majori } \\
\text { Exclusivamente ou majori } \\
\text { Mais ou menos igualmente }\end{array}$ & $\begin{array}{l}\text { iamente garota } \\
\text { iamente rapaze } \\
\text { istos }-\mathrm{M}\end{array}$ & & & $\begin{array}{r}\text { Maioria dos pa } \\
\text { Maior } \\
\text { Mais ou meno }\end{array}$ & $\begin{array}{l}\text { ipantes está } \\
\text { dos participaı } \\
\text { ualmente mi }\end{array}$ & $\begin{array}{l}\text { escola -- S } \\
\text { s está fora da esco } \\
-\mathrm{M}\end{array}$ & ola - O \\
\hline
\end{tabular}

Obs.: Esta planilha e as áreas de programa são relacionadas somente para fins ilustrativos. Num determinado cenário, estas categorias devem ser especificadas de modo a refletir o contexto. 
(2) Population Council

Anexo B.1: Folha de Adesão para Educadores de Pares (Multiplicadores)*

\begin{tabular}{|c|c|c|c|c|c|c|c|c|c|c|}
\hline \begin{tabular}{|l}
$(1)$ \\
$\mathrm{N}^{\circ}$ de \\
Ident. do \\
Educado \\
r de \\
Pares
\end{tabular} & $\begin{array}{l}\text { (2) } \\
\text { Nome }\end{array}$ & $\begin{array}{c}\text { (3) } \\
\text { Organização }\end{array}$ & $\begin{array}{c}\text { (4) } \\
\text { Qual } \\
\text { sua } \\
\text { idade? }\end{array}$ & $\begin{array}{c}(5) \\
\text { Você é } \\
\text { rapaz } \\
\text { ou } \\
\text { garota } \\
?\end{array}$ & $\begin{array}{c}(6) \\
\text { No momento } \\
\text { está } \\
\text { matriculado } \\
\text { na escola? } \\
\text { (Sim/Não) }\end{array}$ & $\begin{array}{c}\text { (7) } \\
\text { Qual é o } \\
\text { grau mais } \\
\text { alto de } \\
\text { escolari- } \\
\text { dade que } \\
\text { você } \\
\text { concluiu? }\end{array}$ & $\begin{array}{c}\text { (8) } \\
\text { Você mora com } \\
\text { ambos os pais, } \\
\text { somente com a } \\
\text { mãe, somente } \\
\text { com o pai, outros } \\
\text { parentes ou } \\
\text { nenhum parente? }\end{array}$ & $\begin{array}{c}\text { (9) } \\
\text { Você é } \\
\text { casado, } \\
\text { nunca casou, } \\
\text { separado, } \\
\text { divorciado ou } \\
\text { viúvo(a)? }\end{array}$ & $\begin{array}{c}(10) \\
\text { Há quanto } \\
\text { tempo você } \\
\text { atua como } \\
\text { educador de } \\
\text { pares? }\end{array}$ & $\begin{array}{c}\text { (11) } \\
\text { Que tipo de } \\
\text { treinamento teve? } \\
\text { Usar códigos. } \\
\text { Informar todos } \\
\text { os assuntos } \\
\text { citados } \\
\text { (múltiplas } \\
\text { escolhas) }\end{array}$ \\
\hline 1 & Maria & $\begin{array}{c}\text { Population } \\
\text { Council }\end{array}$ & 24 & Garota & Não & $\begin{array}{c}1^{2 a} \text { série do } \\
E M\end{array}$ & Ambos os pais & Nunca casou & 3 meses & $1,3,8$ \\
\hline 2 & & & & & & & & & & \\
\hline 3 & & & & & & & & & & \\
\hline 4 & & & & & & & & & & \\
\hline 5 & & & & & & & & & & \\
\hline 6 & & & & & & & & & & \\
\hline 7 & & & & & & & & & & \\
\hline 8 & & & & & & & & & & \\
\hline 9 & & & & & & & & & & \\
\hline 10 & & & & & & & & & & \\
\hline 11 & & & & & & & & & & \\
\hline 12 & & & & & & & & & & \\
\hline 13 & & & & & & & & & & \\
\hline 14 & & & & & & & & & & \\
\hline 15 & & & & & & & & & & \\
\hline
\end{tabular}

* Este formulário deve ser preenchido pelos educadores de pares (multiplicadores).

CÓDIGOS TÍPICOS:

\begin{tabular}{l}
\hline 1= HIVIAIDS \\
2= PLANEJAMENTO \\
FAMILIAR \\
3=DSTS \\
4= GRAVIDEZ \\
5= ABORTO \\
6= FGC \\
\hline
\end{tabular}

\section{$7=$ PRESERVA-TIVOS}

8= CONTRA-CEPÇÃO DE EMERGÊNCIA

$9=$ HIGIENE/SANEAMENTO

$10=$ HABILIDADES PARA A VIDA

$11=$ QUESTÕES/ RELAÇÕES

FAMILIARES E SOCIAIS

12=DROGASIÁLCOOL
13=DELINQUÊNCIA

14=QUESTÕES DE GÊNERO

15= TRÁFICO INFANTIL

16=CASAMENTO

$17=$ DIREITOS INFANTIS

18= OUTROS (FAVOR

ESPECIFICAR NA TABELA) 


\section{Anexo B.2: Formulário de Coleta de Dados para as Organizações.}

1. Nome da organização:

2. Endereço:

3. Em quais cidades / regiões do atua?

Urbana Rural Ambas

4. Quantos educadores de pares (multiplicadores) trabalharam para a entidade em 2005?

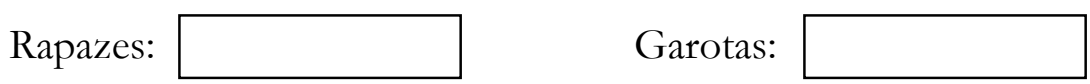

5. Qual é a população-alvo do seu programa de educação de pares? A entidade atinge subgrupos em particular (na escola/fora da escola, mais jovens/mais velhos)?

6. Em quais temas os educadores de pares da entidade foram treinados? (Favor assinalar todos em que for o caso.)

$\begin{array}{lll}\square \text { HIV/AIDS } & \square \text { DSTs } & \square \text { HIGIENE/SANEAMENTO } \\ \square \text { HABIL. VIDA } & \square \text { PRESERVATIVOS } & \square \text { PLANEJAMENTO FAMILIAR } \\ \square \text { GÊNERO } & \square \text { GRAVIDEZ } & \square \text { CONTRACEPÇÃO EMERGÊNCIA } \\ \square \text { ABORTO } & \square \text { DROGAS/ÁLCOOL } & \square \text { CORTE GENITAL FEMININO } \\ \square \text { CASAMENTO } & \square \text { DELINQUÊNCIA } & \square \text { TRÁFICO INFANTIL } \\ \square \text { QUESTÕES/ } & \square \text { DIREITOS INFANTIS } & \square \text { OUTROS (ESPECIFICAR) } — \\ \begin{array}{l}\text { RELAÇÕES FAMI- } \\ \text { LIARES E SOCIAIS. }\end{array} & \end{array}$

7. Em quais atividades os educadores de pares (multiplicadores) estão envolvidos?

$\square$ DISCUSSÃO INDIVIDUAL $\quad \square$ DISCUSSÃO EM GRUPO

$\square$ FORNEC. DE INFORMAÇÕES $\square$ TEATRO

DISTRIB. DE PRESERVATIVOS $\square$ INDICAÇÃO DE SERVIÇOS CLÍNICOS

OUTROS (favor especificar) 
Annex B.3: Registro de Atividades Individuais para Educador de Pares ou Prestador de Serviço

(1) Nome do Prestador de Serviço / Educador de Pares.

( 2 ) Organização

Anote cada pessoa contatada numa única linha.

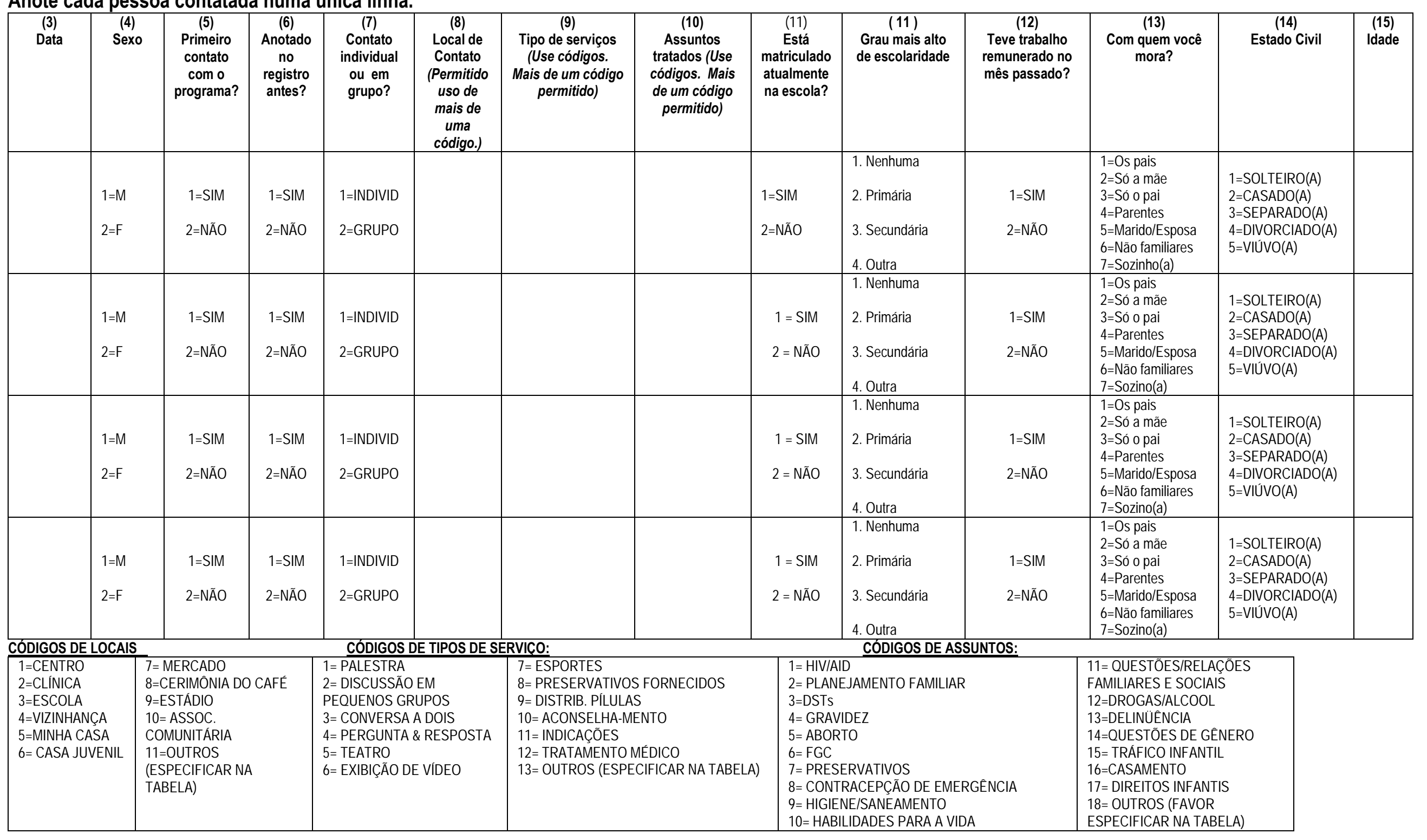




\section{(1) Population Council}

\section{Anexo B.4: Folha de Adesão para Atividades Grupais de Educadores de Pares*}

(1) Nome

( 2 ) Organização

( 3 ) No. Ident. do Educador de Pares

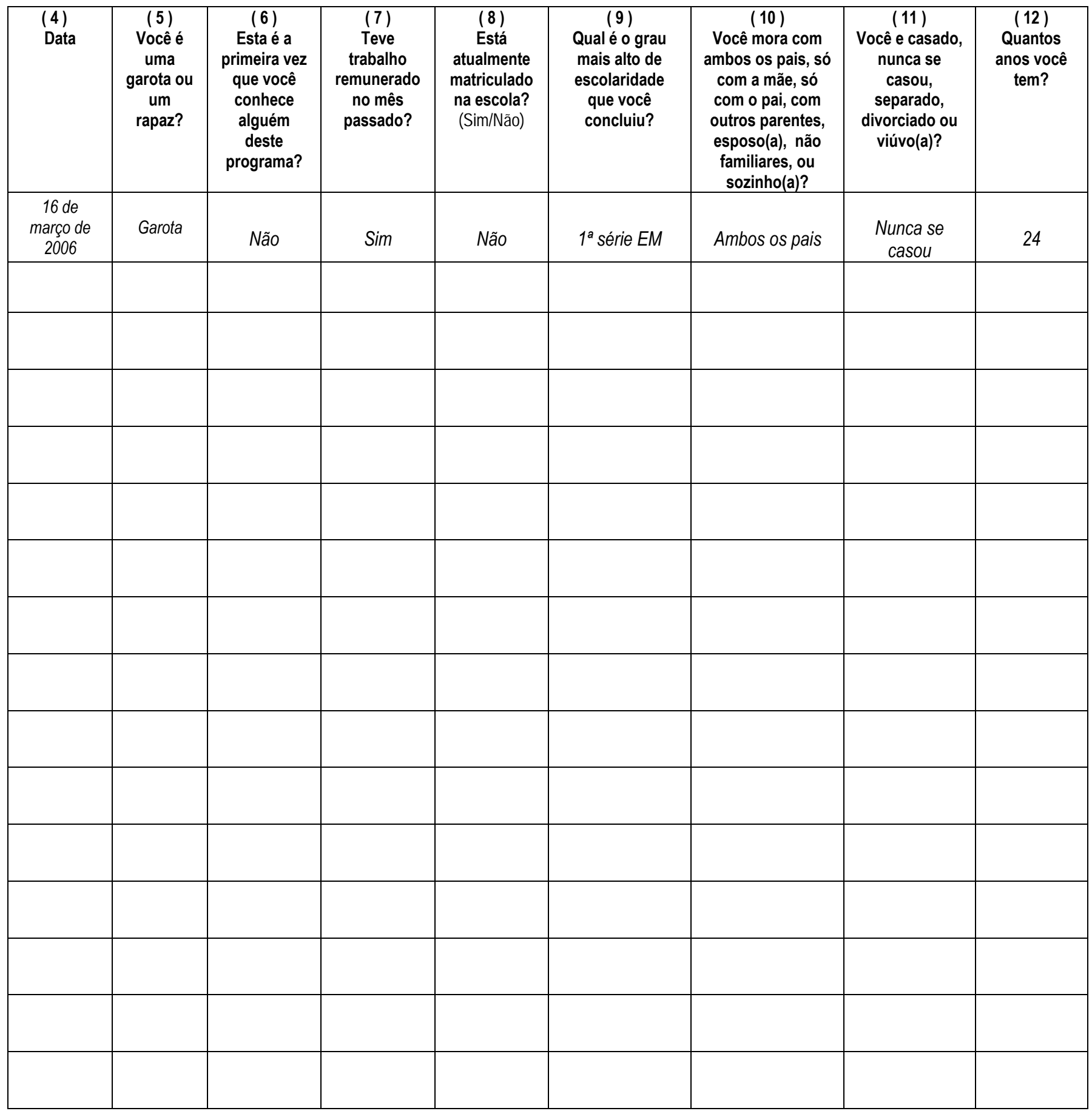

* Este formulário deve ser utilizado quando um educador de pares se reúne com um grupo. 
Anexo B.5 Registro de Atividades para um Centro de Juventude

(1) Nome do Centro de Juventude

Anote o nome de cada pessoa contatada numa única linha.

\begin{tabular}{|c|c|c|c|c|c|c|c|c|c|c|c|c|}
\hline $\begin{array}{l}\text { (2) } \\
\text { Data }\end{array}$ & $\begin{array}{l}\text { (3) } \\
\text { Sexo }\end{array}$ & $\begin{array}{c}\text { ( } 4 \text { ) } \\
\text { Atividades no } \\
\text { centro } \\
\text { Use códigos. } \\
\text { Informe todas as } \\
\text { atividades citadas } \\
\text { (múltiplas } \\
\text { escolhas) }\end{array}$ & $\begin{array}{c}(5) \\
\text { Participou de } \\
\text { um discussão } \\
\text { com amigo/a, } \\
\text { educador de } \\
\text { pares ou o } \\
\text { diretor? }\end{array}$ & $\begin{array}{c}\text { (6) } \\
\text { Assuntos } \\
\text { discutidos hoje } \\
\text { Use códigos. } \\
\text { Informe todos os } \\
\text { assuntos citados } \\
\text { (múltiplas } \\
\text { escolhas) }\end{array}$ & $\begin{array}{c}(7) \\
\text { Já respondeu ao } \\
\text { questionário? }\end{array}$ & $\begin{array}{c}\text { ( } 8 \text { ) } \\
\text { Freqüência } \\
\text { com que visita } \\
\text { o centro }\end{array}$ & $\begin{array}{c}\text { (9) } \\
\text { Está } \\
\text { atual- } \\
\text { mente } \\
\text { matricula } \\
\text { do em } \\
\text { escola? }\end{array}$ & $\begin{array}{c}(10) \\
\text { Grau mais } \\
\text { elevado de } \\
\text { escola- } \\
\text { ridade }\end{array}$ & $\begin{array}{c}\text { (11) } \\
\text { Com quem você } \\
\text { mora? }\end{array}$ & $\begin{array}{c}(12) \\
\text { Teve } \\
\text { trabalho } \\
\text { remuner } \\
\text { ado no } \\
\text { mês } \\
\text { passado } \\
?\end{array}$ & $\begin{array}{c}(13) \\
\text { Estado Civil }\end{array}$ & $\begin{array}{l}\text { (14) } \\
\text { Idade }\end{array}$ \\
\hline & $\begin{array}{l}\text { 1. Rapaz } \\
\text { 2. Garota }\end{array}$ & & $\begin{array}{l}\text { 1. Não } \\
\text { (vá para [6]) } \\
\text { 2. Sim } \\
\text { (continue) }\end{array}$ & & $\begin{array}{l}\text { 1. Não (continue na } \\
\text { próxima coluna) } \\
\text { 2. SIM (FIM: ISe } \\
\text { Sim, passe o } \\
\text { questionário para a } \\
\text { próxima pessoa) }\end{array}$ & $\begin{array}{l}\text { 1. Uma vez } \\
\text { 2. 2-3 vezes } \\
\text { 3. 3-4 vezes } \\
\text { 4. todo dia } \\
\text { 5. menos de uma } \\
\text { vez por semana } \\
\text { mas mais de uma } \\
\text { vez por mês }\end{array}$ & $\begin{array}{l}\text { 1. Sim } \\
\text { 2. Não }\end{array}$ & $\begin{array}{l}\text { 1. Nenhuma } \\
\text { 2. Primária } \\
\text { 3. Secun- } \\
\text { dária } \\
\text { 4. Outra }\end{array}$ & $\begin{array}{l}\text { 1=Ambos os pais } \\
2=\text { =Só com a mãe } \\
3=\text { Só com o pai } \\
\text { 4=Outros } \\
\text { parentes } \\
\text { 5= Marido/Esposa } \\
\text { 6=Não parente } \\
\text { 7=Sozinho(a) }\end{array}$ & $\begin{array}{l}\text { 1. Sim } \\
\text { 2. Não }\end{array}$ & $\begin{array}{l}\text { 1=NUNCA } \\
\text { CASOU } \\
\text { 2=CASADO } \\
\text { 3=SEPARADO } \\
\text { 4=DIVORCIADO } \\
\text { 5=VIÚVO }\end{array}$ & \\
\hline & $\begin{array}{l}\text { 1. Rapaz } \\
\text { 2. Garota }\end{array}$ & & $\begin{array}{l}\text { 1. Não } \\
\text { (vá para [6]) } \\
\text { 2. Sim } \\
\text { (continue) }\end{array}$ & & $\begin{array}{l}\text { 1. Não (continuar na } \\
\text { coluna seguinte) } \\
\text { 2. Sim (FIM: Se } \\
\text { Sim, passe o } \\
\text { questionário para } \\
\text { outra pessoa) }\end{array}$ & $\begin{array}{l}\text { 1. Uma vez } \\
\text { 2. } 2-3 \text { vezes } \\
\text { 3. } 3-4 \text { vezes } \\
\text { 4. todo dia } \\
\text { 5. menos de uma } \\
\text { vez por semana } \\
\text { mas mais de uma } \\
\text { vez por mês }\end{array}$ & $\begin{array}{l}\text { 1. Sim } \\
\text { 2. Não }\end{array}$ & $\begin{array}{l}\text { 1. Nenhuma } \\
\text { 2. Primária } \\
\text { 3. Secun- } \\
\text { dária } \\
\text { 4. Outra }\end{array}$ & $\begin{array}{l}\text { 1=Ambos os pais } \\
2=\text { Só com a mãe } \\
3=\text { Só com o pai } \\
\text { 4=Outros } \\
\text { parentes } \\
\text { 5= Marido/Esposa } \\
\text { 6=Nãp parente } \\
\text { 7=Sozinho(a) }\end{array}$ & $\begin{array}{l}\text { 1. Sim } \\
\text { 2. Não }\end{array}$ & $\begin{array}{l}\text { 1=NUNCA } \\
\text { CASOU } \\
\text { 2=CASADO } \\
\text { 3=SEPARADO } \\
\text { 4=DIVORCIADO } \\
\text { 5=VIÚVO }\end{array}$ & \\
\hline & $\begin{array}{l}\text { 1. Rapaz } \\
\text { 2. Garota }\end{array}$ & & $\begin{array}{l}\text { 1. Não } \\
\text { (vá para [6]) } \\
\text { 2. Sim } \\
\text { (continue) }\end{array}$ & & $\begin{array}{l}\text { 1. Não (continue na } \\
\text { próxima coluna) } \\
\\
\text { 2. SIM (FIM: Se } \\
\text { Sim, passe o } \\
\text { questionário para a } \\
\text { próxima pessoa) }\end{array}$ & $\begin{array}{l}\text { 1. Uma vez } \\
\text { 2. 2-3 vezes } \\
\text { 3. } 3-4 \text { vezes } \\
\text { 4. todo dia } \\
\text { 5. menos de uma } \\
\text { vez por semana } \\
\text { mas mais de uma } \\
\text { vez por mês }\end{array}$ & $\begin{array}{l}\text { 1. Sim } \\
\text { 2. Não }\end{array}$ & $\begin{array}{l}\text { 1. Nenhuma } \\
\text { 2. Primária } \\
\text { 3. Secun- } \\
\text { dária } \\
\text { 4. outra }\end{array}$ & $\begin{array}{l}\text { 1=Ambos os pais } \\
\text { 2=Só com a mãe } \\
\text { 3=Só com o pai } \\
\text { 4=Outros } \\
\text { parentes } \\
\text { 5= Marido/Esposa } \\
\text { 6=Não parente } \\
\text { 7=Sozinho(a) }\end{array}$ & $\begin{array}{l}\text { 1. Sim } \\
\text { 2. Não }\end{array}$ & $\begin{array}{l}\text { 1=NUNCA } \\
\text { CASOU } \\
\text { 2=CASADO } \\
\text { 3=SEPARADO } \\
\text { 4=DIVORCIADO } \\
\text { 5=VIÚVO }\end{array}$ & \\
\hline
\end{tabular}

CÓDIGOD DE ATIVIDADES NO CENTRO:

\section{1=KARATE
2=FUTEBOL}

2=FUTEBOL

3=BASQUETE
4=INFORMÁTICA

5= REUNIÃO ESCOTEIROS

$6=$ TEATRO
CÓDIGOS DOS ASSUNTOS

1= HIVIAIDS

2=PLANEJAMENTO FAMILIAR

$3=$ DSTS

4= GRAVIDEZ

$5=$ ABORTO

$6=\mathrm{FGC}$
7= PRESERVATIVOS

$8=$ CONTRACEPÇÃO DE

EMERGÊNCIA

$9=$ HIGIENE/SANEAMENTO

$10=$ HABILIDADES DE VIDA

$11=$ QUESTÕES/RELACÕES

FAMILIARES E SOCIAIS
12=DROGASIALCOOL

13=DELINQÜÊNCIA

14=QUESTÕES DE GÊNERO

15=TRÁFICO INFANTIL

16=CASAMENTO

17=DIREITOS INFANTIS

18=OUTROS (FAVOR

ESPECIFICAR NA TABELA) 


\title{
Anexo C: Programação utilizada no treinamento ocorrido em Burkina Faso \\ Quem as organizações de atendimento à juventude atingem? Planejamento de uma atividade de exercício de cobertura
}

\author{
08:00 - 08:30 \\ 08:30 - 09:00 \\ 09:00 - 09:15 \\ $09: 15-09: 30$ \\ $09: 30-10: 15$ \\ $10: 15-10: 30$ \\ $10: 30-11: 00$ \\ $11: 00-11: 15$ \\ $11: 15-12: 30$ \\ $12: 30-13: 15$ \\ $13: 15-14: 00$ \\ $14: 00-15: 00$ \\ $15: 00-16: 30$ \\ $16: 30-17: 00$

\section{Credenciamento} \\ Boas-Vindas e introdução às apresentações \\ Objetivos da oficina \\ Adolescentes em Burkina Faso: alguns fatos \\ Apresentação do registro de atividades \\ Breve demonstração por 2 participantes de como utilizá-lo - simulação \\ Intervalo \\ Simulação utilizando os registros de atividade (todos os participantes) \\ Apresentação do registro grupal \\ Simulação utilizando o registro grupal (todos os participantes) \\ Almoço \\ Discussão e perguntas a respeito das simulações encenadas \\ (todos os participantes; 1-2 facilitadores) \\ Mais questões e distribuição de cadernos/pastas \\ (todos os participantes; 1-2 facilitadores) \\ Questões adicionais e discussão \\ Comentários de encerramento, questões administrativas.
}




\section{Anexo D: Amostras de resultados do exercício de cobertura na Mauritânia} (Fonte das tabelas e figuras: UNPFA e Population Council,

Exercício de Cobertura na Mauritânia, 2006)

Tabela 1. Proporções dos sexos das pessoas atendidas nos cinco centros de juventude mais atuantes durante a coleta de dados (os dados foram coletados pelo período de uma semana em cada centro juvenil)

\begin{tabular}{|cccc|}
\hline Centro de Juventude & \multicolumn{3}{c|}{ Gênero } \\
\cline { 2 - 3 } & Masculino (\%) & Feminino (\%) & Número \\
\hline A & 90 & 10 & 541 \\
B & 90 & 10 & 403 \\
C & 97 & 3 & 557 \\
D & 51 & 49 & 385 \\
E & 79 & 21 & 419 \\
\hline Total & $\mathbf{8 3}$ & $\mathbf{1 7}$ & $\mathbf{2 . 3 0 5}$ \\
\hline
\end{tabular}

Tabela 1 mostra que, em todos os centros menos um deles, muitos mais homens que mulheres visitaram ditos centros.

Tabela 2: Distribuição percentual dos indivíduos que vieram aos centros da juventude durante o período da coleta (dados combinados de todos os centros)

\begin{tabular}{|c|c|c|c|c|c|c|c|c|}
\hline \multirow[t]{2}{*}{ Todos os centros } & \multicolumn{7}{|c|}{ Grupo de idade (\%) } & \multirow[t]{2}{*}{ Número } \\
\hline & $<10$ & $10-14$ & $15-19$ & $20-24$ & $25-29$ & $30-34$ & $35+$ & \\
\hline Homens & 4 & 28 & 42 & 15 & 5 & 2 & 3 & 4508 \\
\hline Mulheres & 4 & 28 & 45 & 15 & 5 & 2 & 1 & 944 \\
\hline Total & 4 & 28 & 42 & 15 & 5 & 2 & 3 & 5452 \\
\hline
\end{tabular}

O grupo de 15-19 anos representa mais da metade dos atendidos nos centros. 
Tabela 3: Percentual de distribuição de individuais que vieram ao centro de juventude por gênero, freqüência de visitas por semana (todos os centros juvenis)

\begin{tabular}{|l|c|c|c|c|}
\hline \multirow{2}{*}{$\begin{array}{c}\text { Número de visitas } \\
\text { por semana }\end{array}$} & \multicolumn{2}{|c|}{ Gênero } & Total & Número \\
\cline { 2 - 3 } & Masculino & Feminino & & \\
\hline Uma vez & $\mathbf{1 0}$ & $\mathbf{2 4}$ & $\mathbf{1 3}$ & $\mathbf{7 0 0}$ \\
2 a 3 vezes & 27 & 32 & 28 & 1534 \\
4 a 5 vezes & 17 & 15 & 17 & 922 \\
Todos os dias & $\mathbf{4 0}$ & $\mathbf{2 4}$ & $\mathbf{3 7}$ & $\mathbf{2 0 0 1}$ \\
Menos de uma vez & 6 & 5 & 5 & 295 \\
\hline Total & 100 & 100 & 100 & 5452 \\
\hline
\end{tabular}

Como se pode inferir da Tabela 3, uma parcela significativa de usuários não são usuários repetidos, mas pessoas que freqüentam o centro diariamente - este padrão é particularmente verdadeiro para os rapazes, ao passo que mais garotas do que rapazes visitam os centros somente uma vez por semana.

Tabela 4: Percentual de distribuição de indivíduos por grau de escolaridade e idade (todos os centros de juventude)

\begin{tabular}{|ccccccc|}
\hline \multirow{2}{*}{ Idade } & \multicolumn{7}{c|}{ Grau de Escolaridade } \\
\cline { 2 - 7 } & Nenhum & Primária & Secundária & Corânica & Total & Número \\
\hline$<10$ anos & 0,6 & 87,0 & $\mathbf{1 , 3}$ & 6,1 & 100 & 231 \\
$10-14$ & 0,9 & 75,0 & $\mathbf{2 2 , 5}$ & 1,6 & 100 & 1541 \\
$15-19$ & 1,2 & 15,1 & $\mathbf{8 1 , 0}$ & 2,7 & 100 & 2299 \\
$20-24$ & 3,2 & 24,3 & $\mathbf{6 8 , 6}$ & 3,8 & 100 & 832 \\
$25-29$ & 9,9 & 26,9 & $\mathbf{5 8 , 0}$ & 5,3 & 100 & 283 \\
$30-34$ & 9,3 & 23,3 & $\mathbf{6 5 , 9}$ & 1,6 & 100 & 129 \\
35 ou mais & 6,6 & 15,3 & $\mathbf{7 4 , 5}$ & 3,6 & 100 & 137 \\
\hline Total & 2,4 & 37,3 & $\mathbf{5 7 , 5}$ & 2,8 & 100 & 5452 \\
\hline
\end{tabular}

Como se pode inferir da Tabela 4, observamos que mais da metade de todos os jovens encontrados durante este levantamento estavam no nível escolar secundário embora somente $16,8 \%$ das garotas de 15 a 19 anos tinha em algum momento freqüentado a escola primária - uma cifra que cai para $9,3 \%$ no caso de mulheres entre 20 e 24 anos (de acordo com os dados da pesquisa de DHS de 1998/1999). 
Tabela 5: Distribuição de indivíduos e contatos por gênero e zona de intervenção (a zona de intervenção do doador/patrocinador)

\begin{tabular}{|llll|}
\hline $\begin{array}{c}\text { Teve um intercâmbio com uma } \\
\text { pessoa capacitada ou um amigo } \\
\text { no centro de juventude } \\
\text { \% na coluna) }\end{array}$ & \multicolumn{2}{c|}{ Gênero do contato } & Total \\
\cline { 2 - 3 } & Rapazes & Garotas & $\begin{array}{c}\% \\
(\mathrm{~N})\end{array}$ \\
\hline $\begin{array}{c}\text { Dentro da zona de intervenção } \\
\text { Sim }\end{array}$ & 36 & 60 & 41 \\
Não & 64 & 40 & 59 \\
Total & 100 & 100 & 100 \\
Fora da zona de intervenção & $(2035)$ & $(500)$ & $(2535)$ \\
Sim & 29 & 63 & 34 \\
Não & 71 & 37 & 66 \\
Total & 100 & 100 & 100 \\
& $(4773)$ & $(807)$ & $(5580)$ \\
\hline
\end{tabular}

Figura 1. Proporção de contatos masculinos caracterizados por um intercâmbio com uma pessoa capacitada ou um amigo no centro de juventude, por grupo etário.

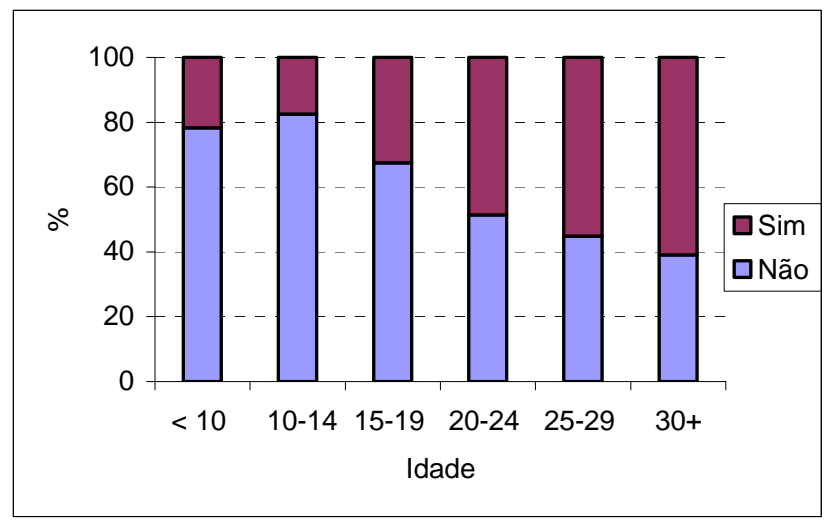


Figura 2. Proporção de contatos femininos caracterizados por um intercâmbio com uma pessoa capacitada ou um amigo no centro de juventude, por grupo etário.

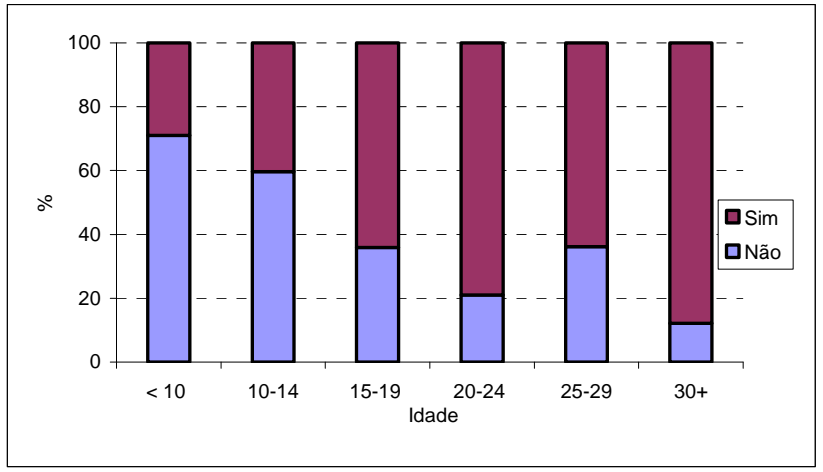




\section{Referências Bibliográficas}

Bruce, Judith. 2003. "Steps in building evidence-based programs for adolescents" in

"Transitions to Adulthood: Adolescent and Youth Sexual and Reproductive Health: Charting directions for a second generation of programming." Background document for the UNFPA/Population Council workshop on Adolescent and Youth Sexual and Reproductive Health: Charting Directions for a Second Generation of Adolescent Programming, New York, 1-3 May 2002.

Demographic and Health Survey. 1999. "Facts about adolescents from the Demographic and Health Survey_Statistical tables for program planning: Burkina Faso 1998-1999." New York, NY:

Population Council.

Mekbib T, Erulkar A, Belete F. 2005. "Who are the targets of youth programs: Results of a capacity building exercise in Ethiopia." Ethiopian Journal of Health Development, Vol. 19(1): 60 -62.

Available on-line at:

http://www.cih.uib.no/journals/EJHD/eihd19-no1/60.Who\%20are\%20the\%20targets\%20of\%20youth\%20programs.pdf

Population Council and UNFPA. 2005. "Exercice de couverture sur les activités des pairs éducateurs au Burkina Faso". See acknowledgments for full list of participants.

Population Council and UNFPA. 2006. "Exercice de couverture sur les activités et la fréquentation des centres de jeunes en Mauritanie." See acknowledgments for full list of participants.

Population Council and UNFPA. 2006. "Exercice de couverture sur les activités des pairs éducateurs en Guinée-Bissau." See acknowledgments for full list of participants.

"Who is being reached by youth programmes? Results from youth-serving organizations' tracking exercise." 2002. Draft presentation. Population Council, PACT Ethiopia, DSW, and Family Guidance Associate of Ethiopia. 